\title{
Cytotoxicity of Plant-Mediated Synthesis of Metallic Nanoparticles: A Systematic Review
}

\author{
Nurul Akma Hanan ${ }^{1}$, Hock Ing Chiu ${ }^{2}$, Muggundha Raoov Ramachandran ${ }^{3}$, Wai Hau Tung ${ }^{4}$, \\ Nur Nadhirah Mohamad Zain ${ }^{2}$, Noorfatimah Yahaya ${ }^{2}$ and Vuanghao Lim ${ }^{2, *}$ (1)
}

1 Active Pharmaceutical Ingredient (API) Section, Centre of Product Registration, National Pharmaceutical Regulatory Agency (NPRA), Lot 36, Jalan Universiti, 46200 Petaling Jaya, Malaysia; nurulakma282@gmail.com

2 Integrative Medicine Cluster, Advanced Medical and Dental Institute, Universiti Sains Malaysia, 13200 Bertam, Penang, Malaysia; hocking6179@gmail.com (H.I.C.); nurnadhirah@usm.my (N.N.M.Z.); noorfatimah@usm.my (N.Y.)

3 Department of Chemistry, Faculty of Science, Universiti Malaya, Kuala Lumpur 50603, Malaysia; muggundha@um.edu.my

4 School of Pharmacy, University of Nottingham Malaysia Campus, Jalan Broga, Semenyih 43500, Malaysia; Tung.WaiHau@nottingham.edu.my

* Correspondence: vlim@usm.my; Tel.: +604-562-2427

Received: 10 April 2018; Accepted: 16 May 2018; Published: 11 June 2018

Abstract: In the field of medicine, nanomaterials, especially those derived using the green method, offer promise as anti-cancer agents and drug carriers. However, the biosafety of metallic nanoparticles used as anti-cancer agents remains a concern. The goal of this systematic review was to compare the cytotoxicity of different plant-mediated syntheses of metallic nanoparticles based on their potency, therapeutic index, and cancer cell type susceptibility in the hopes of identifying the most promising anti-cancer agents. A literature search of electronic databases including Science Direct, PubMed, Springer Link, Google Scholar, and ResearchGate, was conducted to obtain research articles. Keywords such as biosynthesis, plant synthesis, plant-mediated, metallic nanoparticle, cytotoxicity, and anticancer were used in the literature search. All types of research materials that met the inclusion criteria were included in the study regardless of whether the results were positive, negative, or null. The therapeutic index was used as a safety measure for the studied compound of interest. Data from 76 selected articles were extracted and synthesised. Seventy-two studies reported that the cytotoxicity of plant-mediated synthesis of metallic nanoparticles was time and/or dose-dependent. Biosynthesised silver nanoparticles demonstrated higher cytotoxicity potency compared to gold nanoparticles synthesised by the same plants (Plumbago zeylanica, Commelina nudiflora, and Cassia auriculata) irrespective of the cancer cell type tested. This review also identified a correlation between the nanoparticle size and morphology with the potency of cytotoxicity. Cytotoxicity was found to be inversely proportional to nanoparticle size. The plant-mediated syntheses of metallic nanoparticles were predominantly spherical or quasi-spherical, with the median lethal dose of 1-20 $\mu \mathrm{g} / \mathrm{mL}$. Nanoparticles with other shapes (triangular, hexagonal, and rods) were less potent. Metallic nanoparticles synthesised by Abutilon inducum, Butea monosperma, Gossypium hirsutum, Indoneesiella echioides, and Melia azedarach were acceptably safe as anti-cancer agents, as they had a therapeutic index of $>2.0$ when tested on both cancer cells and normal human cells. Most plant-mediated syntheses of metallic nanoparticles were found to be cytotoxic, although some were non-cytotoxic. The results from this study suggest a focus on a selected list of potential anti-cancer agents for further investigations of their pharmacodynamic/toxicodynamic and pharmacokinetic/toxicokinetic actions with the goal of reducing the Global Burden of Diseases and the second leading cause of mortality. 
Keywords: cytotoxicity; plant; synthesis; metallic nanoparticles

\section{Introduction}

Nanotechnology has been embraced by industrial sectors due to the tremendous number of potential applications of nanoparticles and nanomaterials in diverse fields including engineering, telecommunications, advertising, electronics, textiles, space and defence, cosmetics, and medicine. In medicine, nanotechnology is being used to develop new antibacterial and anti-cancer agents in the hopes of devising better treatments and strategies for combating cancer. Cancer is a major health problem worldwide and it is listed as one of the Non-Communicable Diseases in the Global Burden of Diseases. It is the second leading cause of mortality after cardiovascular disease, accounting for the deaths of 8.8 million people worldwide in 2015 [1].

The use of nanoparticles as a potential strategy for combating cancer has been extensively studied since the early 2000s. Recently, researchers have been developing anti-cancer agents using metallic nanoparticles synthesised via various methods, including mechanical attrition, laser ablation, photo reduction, chemical electrolysis, and synthesis by organisms such as bacteria and plants. Biologically synthesised (that is, green) metallic nanoparticles are favoured because chemical and physical methods have many drawbacks, including the use of toxic solvents, generation of hazardous by-products, and high energy consumption [2]. Plant-mediated nanoparticle synthesis is preferred over other techniques because biologically active plant compounds can be exploited as key resources during green synthesis [3]. Additionally, this approach does not involve complicated processes of intracellular synthesis, multiple purifications, and the maintenance of microbial cells [4].

The plant-mediated synthesis of metallic nanoparticles has become increasingly recognised as a mean to produce cytotoxic agents to fight various cancers [5-12]. However, the safety of these synthesised cytotoxic nanomaterials as a treatment remains a huge concern. A potent anti-cancer agent may kill not only cancer cells but also normal healthy cells when used as a treatment. An ideal drug should be selective, specific to the target site, potent ( $<100 \mathrm{mg} /$ day), safe, effective, and have minimal food/drug interactions, convenient dosing frequency, and no requirement for blood level monitoring [13]. Therefore, researchers aim to engineer an anti-cancer agent that has a wide therapeutic index and is stable, specific towards the target site, biocompatible, biodegradable with minimal side effects, reasonably simple to reproduce, and cost-effective.

Hence, the goals of this systematic review were to compare the cytotoxicity potency of the plant-mediated synthesis of metallic nanoparticles based on the results of recently published studies (2006 to 2017); to identify the plant-mediated synthesis of metallic nanoparticles with the most promise as anti-cancer agents based on their potency, cancer cell type susceptibility, and therapeutic index; and to correlate nanoparticles size and morphology with the potency of cytotoxicity.

\section{Results}

The Science Direct database was searched on 11 November 2016, and the process yielded 319 articles. The search of the PubMed database was conducted on 30 November 2016 and yielded 17 articles. On 8 December 2017, the Springer Link database was searched, which produced 291 articles. The Google Scholar search engine was queried on 16 December 2017, resulting in the retrieval of 160 articles. Lastly, 9 articles were retrieved from ResearchGate on 17 December 2017. After the articles were imported, the results from the databases were merged, with a total of 796 articles retrieved. Nineteen duplicates were removed. Abstract screening of the remaining 777 articles identified 671 articles that were unrelated to the research question. Of the remaining 106 articles, 88 met the inclusion criteria and 18 studies were excluded.

The remaining 88 articles were critically appraised using the criteria described in Section 4. Twelve articles were excluded after thorough appraisal. Seven articles were excluded due to 
insufficiently described methodology (for example, duration of exposure not stated clearly for an in vitro study), one study was excluded because the dosing of plant-mediated synthesis of metallic nanoparticles was not specified, and one study was excluded because the experiment was not conducted at body temperature. One other article was excluded because the data for the treatment outcomes were not available. Finally, two articles were excluded because the outcomes for each treatment (such as 24,48 , and $72 \mathrm{~h}$ ) were not reported separately. Thus, 76 studies were included in the qualitative synthesis. Of these, only 18 studies were used for the quantitative synthesis and analysis.

In vitro data were available in 75 studies, whereas in vivo results were only present in 1 study. Twenty-one studies focused on plant-mediated gold nanoparticles alone, 52 studies focused on plant-mediated silver nanoparticles alone, and 3 articles focused on both metals simultaneously.

\subsection{In Vitro Studies}

Table 1 provides the data about the cytotoxicity against cancer cells (in vitro) for each plant used in the synthesising of metallic nanoparticles. Most of the plant-mediated syntheses of metallic nanoparticles (67 studies) showed cytotoxicity to cancer cells such as human epithelial lung carcinoma (A549), hepatocellular carcinoma (Hep3B), gastric adenocarcinoma (AGS), human colon carcinoma (HCT-116), human breast adenocarcinoma (MCF-7), human adenocarcinoma mammary gland (MDA-MB), human epithelioid cervix carcinoma (HeLa), human promyelocytic leukaemia (HL-60), and glioblastoma (U87) cells. 
Table 1. The cytotoxicity of the plant-mediated syntheses of metallic nanoparticles on cancer cells (in vitro).

\begin{tabular}{|c|c|c|c|c|c|c|c|c|c|c|c|}
\hline \multicolumn{2}{|c|}{ Cancer Cell Line } & \multirow{2}{*}{$\frac{\mathrm{LD}_{50} \text { or } \mathrm{IC}_{50}}{\mathrm{NA}}$} & \multirow{2}{*}{$\begin{array}{c}\text { Cell Death } \\
\text { Complete cell death at } 10 \mu \mathrm{g} / \mathrm{mL}\end{array}$} & \multirow{2}{*}{$\begin{array}{c}\begin{array}{c}\text { Exposure } \\
\text { Duration }\end{array} \\
4 \mathrm{~h} \\
\end{array}$} & \multirow{2}{*}{$\begin{array}{c}\text { Response Relationship } \\
\text { Dose-dependent } \\
\end{array}$} & \multirow{2}{*}{$\begin{array}{c}\begin{array}{c}\text { Metallic } \\
\text { Nanoparticle }\end{array} \\
\mathrm{Ag} \\
\end{array}$} & \multirow{2}{*}{$\begin{array}{c}\text { Plant Used } \\
\text { Cassia auriculata } \\
\end{array}$} & \multirow{2}{*}{$\begin{array}{c}\text { Plant Part } \\
\text { Leaf }\end{array}$} & \multirow{2}{*}{$\begin{array}{c}\text { Mechanism of Action } \\
\text { Not studied } \\
\end{array}$} & \multirow{3}{*}{$\begin{array}{l}\text { Ref. } \\
{[14]}\end{array}$} & \multirow{3}{*}{$\begin{array}{l}\text { Yea } \\
201\end{array}$} \\
\hline Lung & A549 & & & & & & & & & & \\
\hline & & $10 \mu \mathrm{g} / \mathrm{mL}$ & Complete cell death $30 \mu \mathrm{g} / \mathrm{mL}$ & $4 \mathrm{~h}$ & Dose-dependent & $\mathrm{Au}$ & Cassia auriculata & Leaf & Not studied & & \\
\hline & & $13.5 \mu \mathrm{g} / \mathrm{mL}$ & $>80 \%$ cell death at $>40 \mu \mathrm{g} / \mathrm{mL}$ & $4 \mathrm{~h}$ & Dose-dependent & $\mathrm{Ag}$ & Jatropha gossypifolia & Stem & Not studied & \multirow{2}{*}{ [15] } & \multirow{2}{*}{201} \\
\hline & & $19.5 \mu \mathrm{g} / \mathrm{mL}$ & $>80 \%$ cell death at $>40 \mu \mathrm{\mu g} / \mathrm{mL}$ & $4 \mathrm{~h}$ & Dose-dependent & $\mathrm{Ag}$ & Jatropha curcus & Stem & Not studied & & \\
\hline & & $20 \mu \mathrm{g} / \mathrm{mL}$ & NA & $24 \mathrm{~h}$ & Dose-dependent & $\mathrm{Ag}$ & Euphorbia nivulia & Latex & Apoptosis & {$[16]$} & 2011 \\
\hline & & $28.125 \mu \mathrm{g} / \mathrm{mL}$ & NA & $24 \mathrm{~h}$ & Dose-dependent & $\mathrm{Ag}$ & $\begin{array}{l}\text { Bauhinia tomentosa } \\
\text { (Kanchini) }\end{array}$ & Leaf & Not studied & [12] & 2015 \\
\hline & & $28.37 \mu \mathrm{g} / \mathrm{mL}$ & NA & $24 \mathrm{~h}$ & Dose-dependent & $\mathrm{Au}$ & Nigella sativa & $\begin{array}{l}\text { Essential oil } \\
\text { from seed }\end{array}$ & Not studied & [17] & 2016 \\
\hline & & $53.2 \mu \mathrm{g} / \mathrm{mL}$ & NA & $24 \mathrm{~h}$ & Time and Dose-dependent & $\mathrm{Ag}$ & Acorous calamus & Rhizome & Apoptosis & {$[18]$} & 2014 \\
\hline & & $80 \mu \mathrm{g} / \mathrm{mL}$ & NA & $24 \mathrm{~h}$ & Dose-dependent & $\mathrm{Ag}$ & Rosa damascena & Flower petal & Not studied & [19] & 2014 \\
\hline & & $100 \mu \mathrm{g} / \mathrm{mL}$ & $<20 \%$ at $500 \mu \mathrm{g} / \mathrm{mL}$ & $36 \mathrm{~h}$ & Dose-dependent & $\mathrm{Ag}$ & Origanum vulgare & Leaf & $\begin{array}{l}\text { Reduce cell proliferation, } \\
\text { increase ROS, DNA } \\
\text { fragmentation, apoptosis }\end{array}$ & [20] & 2013 \\
\hline & & $30 \mu \mathrm{g} / \mathrm{mL}$ & NA & $48 \mathrm{~h}$ & Dose-dependent & $\mathrm{Ag}$ & Indoneesiella echioides & Leaf & Not studied & [5] & 2016 \\
\hline & & $32.1 \mu \mathrm{g} / \mathrm{mL}$ & NA & $48 \mathrm{~h}$ & Time and Dose-dependent & $\mathrm{Ag}$ & Acorous calamus & Rhizome & Apoptosis & [18] & 2014 \\
\hline & & $40 \mu \mathrm{g} / \mathrm{mL}$ & NA & $48 \mathrm{~h}$ & Dose-dependent & $\mathrm{Ag}$ & Gossypium hirsutum & Leaf & $\begin{array}{l}\text { Inhibit cell proliferation, } \\
\text { induce loss of cell } \\
\text { membrane integrity, } \\
\text { apoptosis }\end{array}$ & [21] & 2014 \\
\hline & & NA & $80.2 \%$ at $200 \mathrm{nM}$ & $48 \mathrm{~h}$ & Dose-dependent & $\mathrm{Au}$ & $\begin{array}{l}\text { Illicum verum (Star } \\
\text { Anise) }\end{array}$ & Deseeded pod & Apoptosis & [22] & 2015 \\
\hline & & $\mathrm{NA}$ & $<10 \%$ cell death in $0.01-20 \mu \mathrm{M}$ & $48 \mathrm{~h}$ & Non-cytotoxic & $\mathrm{Au}$ & Genipa americana & Fruit & Not studied & [23] & 2016 \\
\hline \multirow[t]{5}{*}{ Liver } & HepG2 & $6 \mu \mathrm{g} / \mathrm{mL}$ & NA & $24 \mathrm{~h}$ & \multirow{2}{*}{ Time and Dose-dependent } & \multirow{2}{*}{$\mathrm{Au}$} & \multirow{2}{*}{ Cajanus cajan } & \multirow{2}{*}{ Seed coat } & \multirow{2}{*}{ Apoptosis } & \multirow{2}{*}{ [24] } & \multirow{2}{*}{2014} \\
\hline & & NA & $\approx 80 \%$ cell death at $2 \mu \mathrm{g} / \mathrm{mL}$ & $48 \mathrm{~h}$ & & & & & & & \\
\hline & & $49.5 \mu \mathrm{g} / \mathrm{mL}$ & $>80 \%$ cell death at $100 \mu \mathrm{g} / \mathrm{mL}$ & $48 \mathrm{~h}$ & Dose-dependent & $\mathrm{Ag}$ & $\begin{array}{c}\text { Oocimum } \\
\text { kilimandscharicum }\end{array}$ & Stem & Not studied & [6] & 2015 \\
\hline & & $\begin{array}{c}\mathrm{NA}\left(\mathrm{GI}_{50}=\right. \\
93.75 \mu \mathrm{g} / \mathrm{mL})\end{array}$ & $16.39 \%$ cell death at $1 \mathrm{mg} / \mathrm{mL}$ & $48 \mathrm{~h}$ & Dose-dependent & $\mathrm{Ag}$ & Morinda pubescens & Leaf & Not studied & [25] & 2013 \\
\hline & Нер3В & $150 \mu \mathrm{g} / \mathrm{mL}$ & $20 \%$ cell death at $200 \mu \mathrm{g} / \mathrm{mL}$ & $24 \mathrm{~h}$ & Dose-dependent & $\mathrm{Au}$ & Rhus chinensis & Plant gall & Not studied & [26] & 2016 \\
\hline \multirow[t]{2}{*}{ Colorectal } & HCT15 & $8 \mu \mathrm{g} / \mathrm{mL}$ & NA & $24 \mathrm{~h}$ & \multirow{2}{*}{ Time and Dose-dependent } & \multirow{2}{*}{$\mathrm{Ag}$} & \multirow{2}{*}{ Vitex negundo } & \multirow[b]{2}{*}{ Leaf } & \multirow{2}{*}{$\begin{array}{l}\text { Inhibit proliferation, cell } \\
\text { cycle arrest, apoptosis }\end{array}$} & \multirow[b]{2}{*}[27]{} & 2014 \\
\hline & & $4 \mu \mathrm{g} / \mathrm{mL}$ & NA & $48 \mathrm{~h}$ & & & & & & & 2014 \\
\hline
\end{tabular}


Table 1. Cont

\begin{tabular}{|c|c|c|c|c|c|c|c|c|c|c|c|}
\hline \multicolumn{2}{|c|}{ Cancer Cell Line } & $\mathrm{LD}_{50}$ or IC $\mathrm{IC}_{50}$ & Cell Death & $\begin{array}{l}\text { Exposure } \\
\text { Duration }\end{array}$ & Response Relationship & $\begin{array}{c}\text { Metallic } \\
\text { Nanoparticle }\end{array}$ & Plant Used & Plant Part & Mechanism of Action & Ref. & Year \\
\hline & & $20 \mu \mathrm{g} / \mathrm{mL}$ & $\mathrm{NA}$ & $48 \mathrm{~h}$ & Dose-dependent & $\mathrm{Ag}$ & Vitex negundo & Leaf & Apoptosis, cell cycle arrest & {$[28]$} & 2013 \\
\hline & \multirow[t]{2}{*}{ HCT116 } & $100 \mu \mathrm{g} / \mathrm{mL}$ & $>60 \%$ cell death at $400 \mu \mathrm{g} / \mathrm{mL}$ & $24 \mathrm{~h}$ & Dose-dependent & $\mathrm{Ag}$ & Commelina nudiflora & Not stated & Apoptosis & \multirow{2}{*}{ [29] } & \multirow{2}{*}{2016} \\
\hline & & $200 \mu \mathrm{g} / \mathrm{mL}$ & $>70 \%$ cell death at $400 \mu \mathrm{g} / \mathrm{mL}$ & $24 \mathrm{~h}$ & Dose-dependent & $\mathrm{Au}$ & Commelina nudiflora & Not stated & Apoptosis & & \\
\hline & \multirow[t]{12}{*}{ HT29 } & $30 \mu \mathrm{g} / \mathrm{mL}$ & NA & $12 \mathrm{~h}$ & Time and Dose-dependent & $\mathrm{Ag}$ & Couroupita guainensis & Leaf & Not studied & [30] & 2016 \\
\hline & & $6 \mu \mathrm{g} / \mathrm{mL}$ & NA & $24 \mathrm{~h}$ & Time and Dose-dependent & $\mathrm{Ag}$ & Vitex negundo & Leaf & $\begin{array}{l}\text { Inhibit proliferation, cell } \\
\text { cycle arrest, apoptosis }\end{array}$ & [27] & 2014 \\
\hline & & $15 \mu \mathrm{g} / \mathrm{mL}$ & $\mathrm{NA}$ & $24 \mathrm{~h}$ & Time and Dose-dependent & $\mathrm{Ag}$ & Terminalia chebula & Fruit & Not studied & [10] & 2016 \\
\hline & & $23.44 \mu \mathrm{g} / \mathrm{mL}$ & $\mathrm{NA}$ & $24 \mathrm{~h}$ & Dose-dependent & $\mathrm{Ag}$ & Catharanthus roseus & Leaf & Not studied & [31] & 2015 \\
\hline & & $25 \mu \mathrm{g} / \mathrm{mL}$ & $>75 \%$ cell death at $40 \mu \mathrm{g} / \mathrm{mL}$ & $24 \mathrm{~h}$ & Time and Dose-dependent & $\mathrm{Ag}$ & Couroupita guainensis & Leaf & Not studied & [30] & 2016 \\
\hline & & $210 \mu \mathrm{g} / \mathrm{mL}$ & $\mathrm{NA}$ & $24 \mathrm{~h}$ & Dose-dependent & $\mathrm{Au}$ & Abutilon indicum & Leaf & $\begin{array}{l}\text { DNA damage, arrest cell } \\
\text { cycle, apoptosis }\end{array}$ & [32] & 2016 \\
\hline & & $2 \mu \mathrm{g} / \mathrm{mL}$ & $\mathrm{NA}$ & $48 \mathrm{~h}$ & Time and Dose-dependent & $\mathrm{Ag}$ & Vitex negundo & Leaf & $\begin{array}{l}\text { Inhibit proliferation, cell } \\
\text { cycle arrest, apoptosis }\end{array}$ & [27] & 2014 \\
\hline & & $10 \mu \mathrm{g} / \mathrm{mL}$ & NA & $48 \mathrm{~h}$ & Time and Dose-dependent & $\mathrm{Ag}$ & Terminalia chebula & Fruit & Not studied & [10] & 2016 \\
\hline & & $20 \mu \mathrm{g} / \mathrm{mL}$ & $>75 \%$ cell death at $40 \mu \mathrm{g} / \mathrm{mL}$ & $48 \mathrm{~h}$ & Time and Dose-dependent & $\mathrm{Ag}$ & Couroupita guainensis & Leaf & Not studied & [30] & 2016 \\
\hline & & $39.06 \mu \mathrm{g} / \mathrm{mL}$ & NA & $48 \mathrm{~h}$ & Dose-dependent & $\mathrm{Ag}$ & Catharanthus roseus & Leaf & Not studied & [31] & 2015 \\
\hline & & $180 \mu \mathrm{g} / \mathrm{mL}$ & $\mathrm{NA}$ & $48 \mathrm{~h}$ & Dose-dependent & $\mathrm{Au}$ & Abutilon indicum & Leaf & $\begin{array}{l}\text { DNA damage, arrest cell } \\
\text { cycle, apoptosis }\end{array}$ & [32] & 2016 \\
\hline & & $46.88 \mu \mathrm{g} / \mathrm{mL}$ & NA & $72 \mathrm{~h}$ & Dose-dependent & $\mathrm{Ag}$ & Catharanthus roseus & Leaf & Not studied & [31] & 2015 \\
\hline & Cасо-2 & $10 \mu \mathrm{M}$ & $\approx 80 \%$ cell death at $50 \mu \mathrm{M}$ & $48 \mathrm{~h}$ & Dose-dependent & $\mathrm{Ag}$ & Eclipta alba & Leaf & Not studied & [33] & 2015 \\
\hline & \multirow[t]{4}{*}{ Colo 205} & $4 \mu \mathrm{g} / \mathrm{mL}$ & NA & $24 \mathrm{~h}$ & Time and Dose-dependent & $\mathrm{Ag}$ & Abutilon inducum & Leaf & $\begin{array}{l}\text { DNA damage, arrest cell } \\
\text { cycle, apoptosis }\end{array}$ & [32] & 2016 \\
\hline & & $5.5 \mu \mathrm{g} / \mathrm{mL}$ & $\mathrm{NA}$ & $24 \mathrm{~h}$ & Time and Dose-dependent & $\mathrm{Ag}$ & Plumeria alba & Flower petal & Apoptosis & [7] & 2015 \\
\hline & & $3 \mu \mathrm{g} / \mathrm{mL}$ & $\mathrm{NA}$ & $48 \mathrm{~h}$ & Time and Dose-dependent & $\mathrm{Ag}$ & Abutilon inducum & Leaf & $\begin{array}{l}\text { DNA damage, arrest cell } \\
\text { cycle, apoptosis }\end{array}$ & [34] & 2015 \\
\hline & & $4.5 \mu \mathrm{g} / \mathrm{mL}$ & NA & $48 \mathrm{~h}$ & Time and Dose-dependent & $\mathrm{Ag}$ & Plumeria alba & Flower petal & Apoptosis & [7] & 2015 \\
\hline & $\begin{array}{c}\text { C26 } \\
\text { (murine) }\end{array}$ & $\mathrm{NA}$ & $\begin{array}{c}<20 \% \text { at } 6 \mu \mathrm{\mu g} / \mathrm{mL} \text { and }>80 \% \text { at } \\
\quad 8 \mu \mathrm{mL} / \mathrm{mL}\end{array}$ & $24 \mathrm{~h}$ & Dose-dependent & $\mathrm{Ag}$ & Azadirachta indica & Leaf & Not studied & [35] & 2015 \\
\hline \multirow[t]{2}{*}{ Stomach } & AGS & $\mathrm{NA}$ & $\begin{array}{l}<30 \% \text { cell death in } 3.125 \text { to } \\
200 \mu \mathrm{g} / \mathrm{mL} \text { for all duration }\end{array}$ & $8,16,24 \mathrm{~h}$ & $\begin{array}{c}\text { Minimally } \\
\text { Dose-dependent }\end{array}$ & $\mathrm{Au}$ & Tribulus terrestris & Fruit & Apoptosis & [36] & 2016 \\
\hline & MKN 28 & $150 \mu \mathrm{g} / \mathrm{mL}$ & $80 \%$ at $200 \mu \mathrm{g} / \mathrm{mL}$ & $24 \mathrm{~h}$ & Dose-dependent & $\mathrm{Au}$ & Rhus chinensis & Plant gall & Not studied & [26] & 2016 \\
\hline \multirow[t]{2}{*}{ Breast } & \multirow[t]{2}{*}{ MCF7 } & $0.024 \mu \mathrm{g} / \mathrm{mL}$ & NA & $24 \mathrm{~h}$ & Dose-dependent & $\mathrm{Ag}$ & Oleo europaea & Leaf & Not studied & [37] & 2014 \\
\hline & & $4.91 \mu \mathrm{g} / \mathrm{mL}$ & $\mathrm{NA}$ & $24 \mathrm{~h}$ & Dose-dependent & $\mathrm{Ag}$ & Potentilla fulgens & Root & Apoptosis & [11] & 2015 \\
\hline
\end{tabular}


Table 1. Cont

\begin{tabular}{|c|c|c|c|c|c|c|c|c|c|c|}
\hline Cancer Cell Line & $\mathrm{LD}_{50}$ or IC $\mathrm{IC}_{50}$ & Cell Death & $\begin{array}{l}\text { Exposure } \\
\text { Duration }\end{array}$ & Response Relationship & $\begin{array}{c}\text { Metallic } \\
\text { Nanoparticle }\end{array}$ & Plant Used & Plant Part & Mechanism of Action & Ref. & Year \\
\hline & $5 \mu \mathrm{g} / \mathrm{mL}$ & NA & $24 \mathrm{~h}$ & Dose-dependent & $\mathrm{Ag}$ & Dendrophthoe falcata & Leaf & Not studied & [38] & 2014 \\
\hline & $67 \mu \mathrm{g} / \mathrm{mL}$ & NA & $24 \mathrm{~h}$ & Time and Dose-dependent & $\mathrm{Ag}$ & Piper longum & Fruit & Not studied & [39] & 2014 \\
\hline & $217 \mu \mathrm{g} / \mathrm{mL}$ & NA & $24 \mathrm{~h}$ & Dose-dependent & $\mathrm{Ag}$ & Adenium abesum & Leaf & $\begin{array}{l}\text { DNA damage, autophagy } \\
\text { via increased ROS, } \\
\text { apoptosis }\end{array}$ & [40] & 2016 \\
\hline & $7.19 \mu \mathrm{g} / \mathrm{mL}$ & NA & $24 \mathrm{~h}$ & Dose-dependent & $\mathrm{Ag}$ & Cassia fistula & Flower & Apoptosis & [41] & 2015 \\
\hline & $<8 \mu \mathrm{g} / \mathrm{mL}$ & NA & $24 \mathrm{~h}$ & Time and Dose-dependent & $\mathrm{Au}$ & Musa paradisiaca & Pectin & Apoptosis & [42] & 2016 \\
\hline & $20 \mu \mathrm{g} / \mathrm{mL}$ & NA & $24 \mathrm{~h}$ & Dose-dependent & $\mathrm{Ag}$ & Datura inoxia & Leaf & $\begin{array}{l}\text { Growth suppression, cell } \\
\text { cycle arrest, DNA } \\
\text { synthesis reduction, } \\
\text { apoptosis }\end{array}$ & [43] & 2014 \\
\hline & $20 \mu \mathrm{g} / \mathrm{mL}$ & Complete cell death at $50 \mu \mathrm{g} / \mathrm{mL}$ & $24 \mathrm{~h}$ & Dose-dependent & $\mathrm{Ag}$ & Sesbania grandiflora & Leaf & $\begin{array}{l}\text { DNA damage, oxidative } \\
\text { stress induction, apoptosis }\end{array}$ & [44] & 2013 \\
\hline & $30 \mu \mathrm{g} / \mathrm{mL}$ & NA & $24 \mathrm{~h}$ & Dose-dependent & $\mathrm{Ag}$ & Solnum trilobatum & Fruit (unripe) & Apoptosis & [45] & 2015 \\
\hline & $30.5 \mu \mathrm{g} / \mathrm{mL}$ & $\begin{array}{l}\text { Complete cell inhibition at } 100 \\
\mu \mathrm{g} / \mathrm{mL}\end{array}$ & $24 \mathrm{~h}$ & Dose-dependent & $\mathrm{Ag}$ & Coriandrum sativum & Leaf & Not studied & [46] & 2016 \\
\hline & $42.5 \mu \mathrm{g} / \mathrm{mL}$ & $98 \%$ cell inhibition at $100 \mu \mathrm{g} / \mathrm{mL}$ & $24 \mathrm{~h}$ & Dose-dependent & $\mathrm{Ag}$ & Alternanthera tenella & Leaf & Not studied & [47] & 2016 \\
\hline & $50 \mu \mathrm{g} / \mathrm{mL}$ & NA & $24 \mathrm{~h}$ & Time and Dose-dependent & $\mathrm{Ag}$ & Annona squamosa & Leaf & Apoptosis & [48] & 2012 \\
\hline & NA & $\approx 80 \%$ cell death at $2 \mu \mathrm{g} / \mathrm{mL}$ & $24 \mathrm{~h}$ & Inversely Dose-dependent & $\mathrm{Au}$ & $\begin{array}{c}\text { Camellia sinensis, } \\
\text { Coriandrum sativum, } \\
\text { Mentha arvensis, } \\
\text { Phyllanthus amarus, } \\
\text { Artabotrys hexapetalus, } \\
\text { Mimusops elengi, } \\
\text { Syzygium aromaticum, } \\
\text { C. sinensis } \\
\end{array}$ & Leaf & Not studied & [49] & 2015 \\
\hline & $8 \mu \mathrm{g} / \mathrm{mL}$ & NA & $48 \mathrm{~h}$ & Time and Dose-dependent & $\mathrm{Au}$ & Musa paradisiaca & Pectin & Apoptosis & [42] & 2016 \\
\hline & $30 \mu \mathrm{g} / \mathrm{mL}$ & NA & $24 \mathrm{~h}$ & Time and Dose-dependent & $\mathrm{Ag}$ & Annona squamosa & Leaf & Apoptosis & [48] & 2012 \\
\hline & $10 \mu \mathrm{g} / \mathrm{mL}$ & NA & $48 \mathrm{~h}$ & Time and Dose-dependent & $\mathrm{Ag}$ & Malus domestica & Fruit & Not studied & [50] & 2014 \\
\hline & $31.2 \mu \mathrm{g} / \mathrm{mL}$ & NA & $48 \mathrm{~h}$ & Dose-dependent & $\mathrm{Ag}$ & Melia dubia & Leaf & Not studied & [51] & 2014 \\
\hline & $51 \mu \mathrm{g} / \mathrm{mL}$ & NA & $48 \mathrm{~h}$ & Time and Dose-dependent & $\mathrm{Ag}$ & Piper longum & Fruit & Not studied & {$[39]$} & 2014 \\
\hline & $\begin{array}{c}\mathrm{NA}\left(\mathrm{GI}_{50}=\right. \\
257.8 \mu \mathrm{\mu g} / \mathrm{mL})\end{array}$ & NA & $48 \mathrm{~h}$ & Dose-dependent & $\mathrm{Au}$ & Antigonon leptopus & Leaf & Not studied & [52] & 2015 \\
\hline & $0.455 \mu \mathrm{g} / \mathrm{mL}$ & NA & $72 \mathrm{~h}$ & Dose-dependent & $\mathrm{Au}$ & Nelsonia canescens & Leaf & Not studied & [53] & 2016 \\
\hline & NA & $\begin{array}{l}<60 \% \text { cell death at } 5 \mu \mathrm{g} / \mathrm{mL} \\
\text { and above }\end{array}$ & $72 \mathrm{~h}$ & Dose-dependent & $\mathrm{Ag}$ & Acacia & $\begin{array}{l}\text { Lignin from } \\
\text { wood }\end{array}$ & Not studied & {$[54]$} & 2016 \\
\hline & $100 \mu \mathrm{g} / \mathrm{mL}$ & $>80 \%$ cell death at $500 \mu \mathrm{g} / \mathrm{mL}$ & $120 \mathrm{~h}$ & Dose-dependent & $\mathrm{Ag}$ & $\begin{array}{c}\text { Origanum } \\
\text { heracleoticum }\end{array}$ & Leaf & Not studied & {$[55]$} & 2015 \\
\hline
\end{tabular}


Table 1. Cont

\begin{tabular}{|c|c|c|c|c|c|c|c|c|c|c|c|}
\hline \multicolumn{2}{|c|}{ Cancer Cell Line } & $\mathrm{LD}_{50}$ or $\mathrm{IC}_{50}$ & Cell Death & $\begin{array}{l}\text { Exposure } \\
\text { Duration }\end{array}$ & Response Relationship & $\begin{array}{c}\text { Metallic } \\
\text { Nanoparticle }\end{array}$ & Plant Used & Plant Part & Mechanism of Action & Ref. & Year \\
\hline & \multirow[t]{4}{*}{$\begin{array}{l}\text { MDA- } \\
\text { MB-231 }\end{array}$} & $<10 \mu \mathrm{g} / \mathrm{mL}$ & Complete cell death at $10 \mu \mathrm{g} / \mathrm{mL}$ & $4 \mathrm{~h}$ & Dose-dependent & $\mathrm{Ag}$ & Cassia auriculata & Leaf & Not studied & \multirow{2}{*}{ [14] } & \multirow{2}{*}{201} \\
\hline & & $10 \mu \mathrm{g} / \mathrm{mL}$ & Complete cell death at $30 \mu \mathrm{g} / \mathrm{mL}$ & $4 \mathrm{~h}$ & Dose-dependent & $\mathrm{Au}$ & Cassia auriculata & Leaf & Not studied & & \\
\hline & & $<2 \mu \mathrm{g} / \mathrm{mL}$ & NA & $24 \mathrm{~h}$ & Time and Dose-dependent & $\mathrm{Au}$ & Musa paradisiaca & Pectin & Apoptosis & [42] & 2016 \\
\hline & & $2 \mu \mathrm{g} / \mathrm{mL}$ & NA & $48 \mathrm{~h}$ & Dose-dependent & $\mathrm{Au}$ & Musa paradisiaca & Pectin & Apoptosis & [42] & 2016 \\
\hline \multirow[t]{10}{*}{ Cervix } & \multirow[t]{10}{*}{ HeLa } & $51 \mu \mathrm{g} / \mathrm{mL}$ & $88 \%$ cell death at $300 \mu \mathrm{g} / \mathrm{mL}$ & $3 \mathrm{~h}$ & Dose-dependent & $\mathrm{Ag}$ & Iresine herbstii & Leaf & Not studied & [9] & 2012 \\
\hline & & $20 \mu \mathrm{g} / \mathrm{mL}$ & NA & $24 \mathrm{~h}$ & Dose-dependent & $\mathrm{Au}$ & $\begin{array}{l}\text { Podophyllum } \\
\text { hexandrum }\end{array}$ & Leaf & $\begin{array}{l}\text { DNA damage, oxidative } \\
\text { stress induction, apoptosis }\end{array}$ & [56] & 2014 \\
\hline & & $87.32 \mu \mathrm{g} / \mathrm{mL}$ & NA & $24 \mathrm{~h}$ & Dose-dependent & $\mathrm{Ag}$ & $\begin{array}{c}\text { Nothapodytes } \\
\text { nimmoniana }\end{array}$ & Fruit (ripe) & Not studied & [57] & 2016 \\
\hline & & $92.48 \mu \mathrm{g} / \mathrm{mL}$ & NA & $24 \mathrm{~h}$ & Time and Dose-dependent & $\mathrm{Ag}$ & Acorous calamus & Rhizome & Apoptosis & [18] & 2014 \\
\hline & & $28 \mu \mathrm{g} / \mathrm{mL}$ & NA & $48 \mathrm{~h}$ & Dose-dependent & $\mathrm{Ag}$ & Euphorbia antiquorum & Latex & ROS & [58] & 2016 \\
\hline & & $47.77 \mu \mathrm{g} / \mathrm{mL}$ & NA & $48 \mathrm{~h}$ & Dose-dependent & $\mathrm{Au}$ & Albizia amara & Leaf & Not studied & [59] & 2017 \\
\hline & & $62.5 \mu \mathrm{g} / \mathrm{mL}$ & $\begin{array}{c}\text { Almost } 100 \% \text { cell death at } \\
1000 \mu \mathrm{g} / \mathrm{mL}\end{array}$ & $48 \mathrm{~h}$ & Dose-dependent & $\mathrm{Au}$ & Punica granatum & Fruit & Not studied & {$[60]$} & 2014 \\
\hline & & $69.44 \mu \mathrm{g} / \mathrm{mL}$ & NA & $48 \mathrm{~h}$ & Time and Dose-dependent & $\mathrm{Ag}$ & Acorous calamus & Rhizome & Apoptosis & [18] & 2014 \\
\hline & & $\begin{array}{c}\mathrm{NA}\left(\mathrm{GI}_{50}=\right. \\
34.5 \mathrm{\mu g} / \mathrm{mL})\end{array}$ & NA & $48 \mathrm{~h}$ & Dose-dependent & $\mathrm{Ag}$ & Cymodocea serrulata & Whole plant & Not studied & [61] & 2015 \\
\hline & & $300 \mu \mathrm{g} / \mathrm{mL}$ & NA & $48-72 \mathrm{~h}$ & Dose-dependent & $\mathrm{Ag}$ & Melia azedarach & Leaf & Apoptosis & [62] & 2012 \\
\hline \multirow[t]{2}{*}{ Brain } & \multirow[t]{2}{*}{ U87 } & $8.23 \mu \mathrm{g} / \mathrm{mL}$ & NA & $24 \mathrm{~h}$ & Dose-dependent & $\mathrm{Ag}$ & Potentilla fulgens & Root & Apoptosis & [11] & 2015 \\
\hline & & $1.5 \mathrm{ng} / \mathrm{mL}$ & NA & $48 \mathrm{~h}$ & Dose-dependent & $\mathrm{Au}$ & Hibiscus sabdariffa & $\begin{array}{l}\text { Leaf and stem } \\
\text { (optimal: leaf) }\end{array}$ & $\begin{array}{l}\text { GADPH enzyme } \\
\text { degradation }\end{array}$ & [8] & 2016 \\
\hline \multirow[t]{8}{*}{ Blood } & \multirow[t]{3}{*}{ HL-60 } & $2 \mathrm{mmol} / \mathrm{L}$ & NA & $6 \mathrm{~h}$ & \multirow[t]{2}{*}{ Time and Dose-dependent } & \multirow[t]{2}{*}{$\mathrm{Ag}$} & \multirow{2}{*}{ Eucalyptus chapmania } & \multirow{2}{*}{ Leaf } & \multirow[t]{2}{*}{ Not studied } & \multirow[t]{2}{*}{ [63] } & \multirow[t]{2}{*}{2013} \\
\hline & & $1 \mathrm{mmol} / \mathrm{L}$ & NA & $24 \mathrm{~h}$ & & & & & & & \\
\hline & & $5.14 \mu \mathrm{M}$ & NA & $120 \mathrm{~h}$ & Dose-dependent & $\mathrm{Au}$ & Couroupita guianensis & Flower & Apoptosis & [64] & 2013 \\
\hline & \multirow[t]{4}{*}{ Jurkat } & $13.64 \mu \mathrm{g} / \mathrm{mL}$ & NA & $24 \mathrm{~h}$ & Dose-dependent & $\mathrm{Ag}$ & Abelmoschus esculentus & Pulp & ROS and NO production & [65] & 2015 \\
\hline & & $27.35 \mu \mathrm{g} / \mathrm{mL}$ & NA & $24 \mathrm{~h}$ & \multirow{2}{*}{ Dose-dependent } & \multirow{3}{*}{$\mathrm{Ag}$} & \multirow{3}{*}{ Catharanthus roseus } & \multirow{3}{*}{ Leaf } & \multirow{3}{*}{ Not studied } & \multirow{3}{*}{ [31] } & \multirow{3}{*}{201} \\
\hline & & $39.06 \mu \mathrm{g} / \mathrm{mL}$ & NA & $48 \mathrm{~h}$ & & & & & & & \\
\hline & & $46.88 \mu \mathrm{g} / \mathrm{mL}$ & NA & $72 \mathrm{~h}$ & Dose-dependent & & & & & & \\
\hline & KG-1A & $11.47 \mu \mathrm{g} / \mathrm{mL}$ & NA & $24 \mathrm{~h}$ & Dose-dependent & $\mathrm{Ag}$ & Butea monosperma & Bark & Apoptosis & [66] & 2015 \\
\hline \multirow[t]{3}{*}{ Bone } & \multirow[t]{3}{*}{ MG63 } & $150 \mu \mathrm{g} / \mathrm{mL}$ & $80 \%$ at $200 \mu \mathrm{g} / \mathrm{mL}$ & $24 \mathrm{~h}$ & Dose-dependent & $\mathrm{Au}$ & Rhus chinensis & Plant gall & Not studied & [26] & 2016 \\
\hline & & $\begin{array}{c}75.5 \pm \\
2.4 \mu \mathrm{g} / \mathrm{mL}\end{array}$ & NA & $48 \mathrm{~h}$ & Dose-dependent & $\mathrm{Ag}$ & Ficus benghalensis & Bark & Not studied & \multirow{2}{*}{ [67] } & \multirow{2}{*}{2016} \\
\hline & & $\begin{array}{c}81.8 \pm \\
2.6 \mu \mathrm{g} / \mathrm{mL}\end{array}$ & NA & $48 \mathrm{~h}$ & Dose-dependent & $\mathrm{Ag}$ & Azadirachta indica & Bark & Not studied & & \\
\hline
\end{tabular}


Table 1. Cont.

\begin{tabular}{|c|c|c|c|c|c|c|c|c|c|c|c|}
\hline \multicolumn{2}{|c|}{ Cancer Cell Line } & \multirow{2}{*}{$\begin{array}{c}\mathrm{LD}_{50} \text { or } \mathrm{IC}_{50} \\
\mathrm{NA}\end{array}$} & \multirow{2}{*}{$\begin{array}{c}\text { Cell Death } \\
<5 \% \text { cell death at up to } 200 \mu \mathrm{M}\end{array}$} & \multirow{2}{*}{$\begin{array}{c}\begin{array}{c}\text { Exposure } \\
\text { Duration }\end{array} \\
6-24 \mathrm{~h} \\
\end{array}$} & \multirow{2}{*}{$\begin{array}{c}\text { Response Relationship } \\
\text { Non-cytotoxic }\end{array}$} & \multirow{2}{*}{$\begin{array}{c}\begin{array}{c}\text { Metallic } \\
\text { Nanoparticle }\end{array} \\
\mathrm{Au}\end{array}$} & \multirow{2}{*}{$\begin{array}{c}\text { Plant Used } \\
\text { Dysosma pleiantha }\end{array}$} & \multirow{2}{*}{$\begin{array}{l}\text { Plant Part } \\
\text { Rhizome }\end{array}$} & \multirow{2}{*}{$\begin{array}{l}\text { Mechanism of Action } \\
\text { Cell migration inhibition } \\
\text { via Rac1 mediated actin } \\
\text { polymerization pathway }\end{array}$} & \multirow{2}{*}{$\begin{array}{l}\text { Ref. } \\
{[68]}\end{array}$} & \multirow{2}{*}{$\begin{array}{l}\text { Yea } \\
2013\end{array}$} \\
\hline Connective tissue & HT1080 & & & & & & & & & & \\
\hline \multirow{2}{*}{ Prostate } & \multirow{2}{*}{$\begin{array}{l}\text { LNCap- } \\
\text { FGC }\end{array}$} & $<10 \mu \mathrm{g} / \mathrm{mL}$ & Complete cell death at $10 \mu \mathrm{g} / \mathrm{mL}$ & $4 \mathrm{~h}$ & Dose-dependent & $\mathrm{Ag}$ & Cassia auriculata & Leaf & Not studied & \multirow{2}{*}{ [14] } & \multirow{2}{*}{2015} \\
\hline & & $10 \mu \mathrm{g} / \mathrm{mL}$ & Complete cell death at $30 \mu \mathrm{g} / \mathrm{mL}$ & $4 \mathrm{~h}$ & Dose-dependent & $\mathrm{Au}$ & Cassia auriculata & Leaf & Not studied & & \\
\hline Skin & A375 & $\mathrm{NA}$ & $>75 \%$ cell death at $5 \mu \mathrm{g} / \mathrm{mL}$ & $72 \mathrm{~h}$ & Dose-dependent & $\mathrm{Ag}$ & Acacia & $\begin{array}{l}\text { Lignin from } \\
\text { wood }\end{array}$ & Not studied & [54] & 2016 \\
\hline \multirow[t]{2}{*}{ Throat } & \multirow[t]{2}{*}{ Hep-2 } & $20 \mu \mathrm{g} / \mathrm{mL}$ & Complete cell death at $40 \mu \mathrm{g} / \mathrm{mL}$ & $24 \mathrm{~h}$ & Dose-dependent & $\mathrm{Ag}$ & Phyllanthus emblica & Fruit & $\begin{array}{c}\text { Cell proliferation } \\
\text { reduction, ROS } \\
\text { production, DNA } \\
\text { fragmentation, apoptosis }\end{array}$ & [69] & 2013 \\
\hline & & $31.25 \mu \mathrm{g} / \mathrm{mL}$ & $94.02 \%$ at $500 \mu \mathrm{g} / \mathrm{mL}$ & $24 \mathrm{~h}$ & Dose-dependent & $\mathrm{Ag}$ & Piper longum & Leaf & ROS & [70] & 2012 \\
\hline \multirow{2}{*}{\multicolumn{2}{|c|}{$\begin{array}{l}\text { Dalton's Ascites } \\
\text { Lymphoma (DAL) }\end{array}$}} & NA & $65.61 \%$ cell death at $150 \mu \mathrm{g} / \mathrm{mL}$ & $24 \mathrm{~h}$ & Dose-dependent & $\mathrm{Ag}$ & \multirow{2}{*}{ Plumbago zeylanica } & \multirow{2}{*}{ Bark } & \multirow{2}{*}{ Not studied } & \multirow{2}{*}{ [71] } & \multirow{2}{*}{2016} \\
\hline & & $\mathrm{NA}$ & $61.56 \%$ cell death at $150 \mu \mathrm{g} / \mathrm{mL}$ & $24 \mathrm{~h}$ & Dose-dependent & $\mathrm{Au}$ & & & & & \\
\hline
\end{tabular}

NA = Not Available. 
The table shows that the cytotoxicity of the synthesised nanoparticles is time and/or dose-dependent. However, gold nanoparticles synthesised from Genipa Americana fruit were non-cytotoxic. Although the gold nanoparticles synthesised from the Dysosma pleiantha rhizome showed no cytotoxicity to human fibrosarcoma (HT1080) cells over the tested durations, the study highlighted their anti-metastatic property by cell migration inhibition via the Rac1-mediated actin polymerisation pathway [68]. Overall, the silver nanoparticles had a higher cytotoxicity potency than gold nanoparticles when the same plants (Plumbago zeylanica, Commelina nudiflora, and Cassia auriculata) were used for the synthesis, irrespective of the cancer cell type tested $[5,14,71]$.

The most potent cytotoxic plant-mediated synthesis of the metallic nanoparticles was the silver nanoparticles synthesised by Oleo europaea (Olive) leaves: an $\mathrm{LD}_{50}$ of only $24 \mathrm{ng} / \mathrm{mL}$ over $24 \mathrm{~h}$ was needed to kill breast cancer (MCF-7) cells. Silver nanoparticles derived from Cassia auriculata leaves were the most potent in eradicating lung cancer (A549) cells: 100\% cell death occurred in all tested concentrations, with $10 \mu \mathrm{g} / \mathrm{mL}$ being the minimum tested dose. Gold nanoparticles derived from the leaves of the same plant also led to the complete cancer cell death at a dose of $30 \mu \mathrm{g} / \mathrm{mL}$. Cajanus cajan (Pigeon pea)-mediated gold nanoparticles had an $\mathrm{LD}_{50}$ of $6 \mu \mathrm{g} / \mathrm{mL}$ over the course of $24 \mathrm{~h}$ on liver cancer (HepG2) cells. Iresine herbstii-mediated silver nanoparticles were the most effective at killing cervical cancer (HeLa) cells over $3 \mathrm{~h}$ with an $\mathrm{LD}_{50}$ of $51 \mu \mathrm{g} / \mathrm{mL}$.

Twenty-five of the selected studies tested the cytotoxicity of plant-mediated syntheses of metallic nanoparticles on normal cells (Table 2), which included human lymphocytes, peripheral blood mononuclear cells (PBMC), human breast epithelial cells (HBL100), human keratinocytes (HaCaT), human foetal lung cells (WI-38), African green monkey kidney cells (Vero), mouse fibroblasts (L929), and other cells.

Twenty-four of the studies of plant-mediated synthesis of metallic nanoparticles reported timeand/or dose-dependent cytotoxicity against normal healthy cells. However, four studies reported a contradictory effect. Gold nanoparticles synthesised from Mangifera indica (Mango) peel and Genipa Americana fruit resulted in $<20 \%$ normal cell death for the entire tested dose over the duration of exposure. Silver nanoparticles biosynthesised using the Oleo europaea (Olive) leaf and Nyctanthes arbortristis (Night Jasmine) flower also caused $<20 \%$ normal cell death for the entire tested doses over the duration of exposure. Metallic nanoparticles derived from the Mango peel, Genipa Americana fruit, and Night Jasmine flower showed no cytotoxic activity, which suggests that the use of these plants as drug-delivering carriers in future medicinal products would be safe. Table 1 shows that the Oleo europaea-derived silver nanoparticles have good potency against breast cancer (MCF7) cells, but they do not eradicate normal healthy cells (Table 2). This indicates that the cytotoxicity of these silver nanoparticles was selective towards the tested cancer cells.

\subsection{In Vivo Studies}

The preliminary search results included two studies in which the in vivo cytotoxicity of plant-mediated synthesis of metallic nanoparticles was studied. They were conducted using Dalton's ascites lymphoma (DAL) mouse model and adult zebrafish (Danio rerio). However, only the zebrafish study met all of the required criteria for a quality assessment of the study. Table 3 provides the study description and mortality and cytotoxicity results for the in vivo plant-mediated synthesis of metallic nanoparticles. Silver nanoparticles were synthesised using Malva crispa leaves. The median lethal dose was $142.2 \mathrm{ng} / \mathrm{mL}$, and $100 \%$ mortality occurred at 331.8 and $284.4 \mathrm{ng} / \mathrm{mL}$ at 48 and $96 \mathrm{~h}$, respectively. The cytotoxicity of the plant-mediated synthesis of metallic nanoparticles was prominent as the cell membranes of adult zebrafish gill tissues were damaged and gill cells were destroyed. 
Table 2. The cytotoxicity of plant-mediated syntheses of metallic nanoparticle on normal cells (in vitro).

\begin{tabular}{|c|c|c|c|c|c|c|c|c|c|c|c|}
\hline \multicolumn{2}{|c|}{ Healthy Cell Line } & \multirow{2}{*}{$\begin{array}{c}\mathrm{LD}_{50} \text { or IC } \mathrm{IC}_{50} \\
\mathrm{NA}\end{array}$} & \multirow{2}{*}{$\begin{array}{c}\text { Cell Death } \\
\begin{array}{c}<0 \% \text { cell death at } \\
6 \mu \mathrm{mg} / \mathrm{mL}\end{array}\end{array}$} & \multirow{2}{*}{$\begin{array}{c}\begin{array}{c}\text { Exposure } \\
\text { Duration }\end{array} \\
24 \mathrm{~h}\end{array}$} & \multirow{2}{*}{$\begin{array}{c}\text { Response Relationship } \\
\text { Dose-dependent }\end{array}$} & \multirow{2}{*}{$\begin{array}{c}\begin{array}{c}\text { Metallic } \\
\text { Nanoparticle }\end{array} \\
\mathrm{Ag}\end{array}$} & \multirow{2}{*}{$\begin{array}{c}\text { Plant Used } \\
\text { Potentilla fulgens }\end{array}$} & \multirow{2}{*}{$\begin{array}{c}\text { Plant Part } \\
\text { Root }\end{array}$} & \multirow{2}{*}{$\begin{array}{c}\text { Mechanism of Action } \\
\text { Apoptosis }\end{array}$} & \multirow{2}{*}{$\begin{array}{l}\text { Ref. } \\
{[11]}\end{array}$} & \multirow{2}{*}{$\begin{array}{l}\text { Yea } \\
201\end{array}$} \\
\hline Blood & Lymphocyte & & & & & & & & & & \\
\hline & PBMC & $43.18 \mu \mathrm{g} / \mathrm{mL}$ & NA & $24 \mathrm{~h}$ & Dose-dependent & $\mathrm{Ag}$ & Butea monosperma & Bark & Apoptosis & [66] & 2015 \\
\hline & & $113.25 \mu \mathrm{M}$ & NA & $120 \mathrm{~h}$ & Dose-dependent & $\mathrm{Au}$ & Couroupita guianensis & Flower & Apoptosis & [64] & 2013 \\
\hline & & $\mathrm{NA}$ & $\begin{array}{l}<20 \% \text { cell death in } \\
0.008 \text { to } \\
0.04 \mu \mathrm{gg} / \mathrm{mL}\end{array}$ & $24 \mathrm{~h}$ & NA & $\mathrm{Ag}$ & Oleo europaea & Leaf & Not studied & [37] & 2014 \\
\hline \multirow[t]{5}{*}{ Breast } & HBL100 & $80 \mu \mathrm{g} / \mathrm{mL}$ & NA & $24 \mathrm{~h}$ & Time and Dose-dependent & $\mathrm{Ag}$ & Annona squamosa & Leaf & Apoptosis & [48] & 2012 \\
\hline & & $60 \mu \mathrm{g} / \mathrm{mL}$ & NA & $48 \mathrm{~h}$ & Dose-dependent & $\mathrm{Ag}$ & Indoneesiella echioides & Leaf & Not studied & [5] & 2016 \\
\hline & & $60 \mu \mathrm{g} / \mathrm{mL}$ & NA & $48 \mathrm{~h}$ & Time and Dose-dependent & $\mathrm{Ag}$ & Annona squamosa & Leaf & Apoptosis & [48] & 2012 \\
\hline & & $80 \mu \mathrm{g} / \mathrm{mL}$ & NA & $48 \mathrm{~h}$ & Dose-dependent & $\mathrm{Ag}$ & Gossypium hirsutum & Leaf & $\begin{array}{l}\text { Inhibit cell proliferation, } \\
\text { induce loss of cell membrane } \\
\text { integrity, apoptosis }\end{array}$ & [21] & 2014 \\
\hline & & $750 \mu \mathrm{g} / \mathrm{mL}$ & NA & $48-72 \mathrm{~h}$ & Dose-dependent & $\mathrm{Ag}$ & Melia azedarach & Leaf & Apoptosis & [62] & 2012 \\
\hline \multirow[t]{3}{*}{ Colon } & Normal colon & $50 \mu \mathrm{g} / \mathrm{mL}$ & NA & $12 \mathrm{~h}$ & Time and Dose-dependent & \multirow{3}{*}{$\mathrm{Ag}$} & \multirow{3}{*}{ Couroupita guainensis } & \multirow{3}{*}{ Leaf } & \multirow{3}{*}{ Not studied } & \multirow{3}{*}{ [30] } & \multirow{3}{*}{201} \\
\hline & & $40 \mu \mathrm{g} / \mathrm{mL}$ & NA & $24 \mathrm{~h}$ & \multirow{2}{*}{$\begin{array}{l}\text { Time and Dose-dependent } \\
\text { with saturation effect }\end{array}$} & & & & & & \\
\hline & & $40 \mu \mathrm{g} / \mathrm{mL}$ & NA & $48 \mathrm{~h}$ & & & & & & & \\
\hline \multirow[t]{7}{*}{ Skin } & $\mathrm{HaCaT}$ & $1000 \mu \mathrm{g} / \mathrm{mL}$ & NA & $24 \mathrm{~h}$ & Tim and Doc-denend & & & & DNA damage, arrest cell & [201 & \\
\hline & & $900 \mu \mathrm{g} / \mathrm{mL}$ & NA & $48 \mathrm{~h}$ & Time and Dose-dependent & $\mathrm{Au}$ & Abutilon indicum & Leaf & cycle, apoptosis & [32] & 2016 \\
\hline & & NA & $\begin{array}{l}<2 \% \text { at }<6 \mu \mathrm{gg} / \mathrm{mL} \\
\text { and }>75 \% \% \text { at } \\
>8 \mu \mathrm{\mu g} / \mathrm{mL}\end{array}$ & $24 \mathrm{~h}$ & Dose-dependent & $\mathrm{Ag}$ & Azadirachta indica & Leaf & Not studied & [35] & 2015 \\
\hline & HSFs & $\mathrm{NA}$ & $\begin{array}{c}>50 \% \text { cell death in } \\
16-80 \mu \mathrm{g} / \mathrm{mL}\end{array}$ & $24 \mathrm{~h}$ & $\begin{array}{l}\text { Dose-dependent with } \\
\text { saturation effect }\end{array}$ & \multirow{4}{*}{$\mathrm{Ag}$} & \multirow{4}{*}{ Theobroma cacao } & Beans (S4H formula) & \multirow{4}{*}{ Not studied } & \multirow{4}{*}{ [72] } & \multirow{4}{*}{201} \\
\hline & & $\mathrm{NA}$ & $\begin{array}{l}>50 \% \text { cell death at } \\
80 \mu \mathrm{g} / \mathrm{mL}\end{array}$ & $24 \mathrm{~h}$ & Dose-dependent & & & Beans (S3H formula) & & & \\
\hline & & $\mathrm{NA}$ & $\begin{array}{c}>50 \% \text { cell death at } \\
16 \mu \mathrm{g} / \mathrm{mL}\end{array}$ & $72 \mathrm{~h}$ & Dose-dependent & & & Beans (S3H formula) & & & \\
\hline & & $\mathrm{NA}$ & $\begin{array}{l}>50 \% \text { cell death in } \\
16-80 \mu \mathrm{g} / \mathrm{mL}\end{array}$ & $72 \mathrm{~h}$ & $\begin{array}{l}\text { Dose-dependent with } \\
\text { saturation effect }\end{array}$ & & & Beans ( $\mathrm{S} 4 \mathrm{H}$ formula) & & & \\
\hline Foetallung & W1-38 & $\mathrm{NA}$ & $\begin{array}{l}<20 \% \text { cell death in } \\
10 \text { to } 160 \mu \mathrm{g} / \mathrm{mL}\end{array}$ & $24 \mathrm{~h}$ & Non cytotoxic & $\mathrm{Au}$ & Mangifera indica & Peel & NA & [73] & 2014 \\
\hline
\end{tabular}


Table 2. Cont.

\begin{tabular}{|c|c|c|c|c|c|c|c|c|c|c|c|}
\hline \multicolumn{2}{|c|}{ Healthy Cell Line } & $\mathrm{LD}_{50}$ or IC 50 & Cell Death & $\begin{array}{l}\text { Exposure } \\
\text { Duration }\end{array}$ & Response Relationship & $\begin{array}{l}\text { Metallic } \\
\text { Nanoparticle }\end{array}$ & Plant Used & Plant Part & Mechanism of Action & Ref. & Year \\
\hline \multirow[t]{14}{*}{ Kidney } & $\begin{array}{l}\text { Embryonic human } \\
\text { kidney (293) }\end{array}$ & $\begin{array}{l}\mathrm{NA}\left(\mathrm{LD}_{20}=\right. \\
2 \mathrm{ng} / \mathrm{mL})\end{array}$ & NA & $48 \mathrm{~h}$ & Dose-dependent & $\mathrm{Au}$ & Hibiscus sabdariffa & $\begin{array}{l}\text { Leaf and stem (leaf } \\
\text { gives optimal yield) }\end{array}$ & GADPH enzyme degradation & [8] & 2016 \\
\hline & \multirow{2}{*}{$\begin{array}{l}\text { Madin Darby canine } \\
\text { kidney (MDCK) }\end{array}$} & $100 \mu \mathrm{g} / \mathrm{mL}$ & NA & $24 \mathrm{~h}$ & \multirow{2}{*}{ Time and Dose-dependent } & \multirow{2}{*}{$\mathrm{Ag}$} & \multirow{2}{*}{ Abutilon inducum } & \multirow{2}{*}{ Leaf } & \multirow{2}{*}{$\begin{array}{l}\text { DNA damage, arrest cell } \\
\text { cycle, apoptosis }\end{array}$} & \multirow{2}{*}{ [32] } & \multirow{2}{*}{2016} \\
\hline & & $75 \mu \mathrm{g} / \mathrm{mL}$ & NA & $48 \mathrm{~h}$ & & & & & & & \\
\hline & \multirow{10}{*}{$\begin{array}{l}\text { African green monkey } \\
\text { kidney (Vero) }\end{array}$} & $20 \mu \mathrm{g} / \mathrm{mL}$ & NA & $24 \mathrm{~h}$ & Time and Dose-dependent & $\mathrm{Ag}$ & Terminalia chebula & Fruit & Not studied & [10] & 2016 \\
\hline & & $66.34 \mu \mathrm{g} / \mathrm{mL}$ & NA & $24 \mathrm{~h}$ & Dose-dependent & $\mathrm{Ag}$ & Cassia fistula & Flower & Apoptosis & [41] & 2015 \\
\hline & & $246 \mu \mathrm{g} / \mathrm{mL}$ & NA & $24 \mathrm{~h}$ & Dose-dependent & $\mathrm{Au}$ & Cajanus cajan & Seed coat & Apoptosis & [24] & 2014 \\
\hline & & NA & $\begin{array}{c}72.8 \% \text { cell } \\
\text { inhibition at } \\
20 \mu \mathrm{g} / \mathrm{mL}\end{array}$ & $24 \mathrm{~h}$ & Dose-dependent & $\mathrm{Ag}$ & Datura inoxia & Leaf & $\begin{array}{l}\text { Growth suppression, cell } \\
\text { cycle arrest, DNA synthesis } \\
\text { reduction, apoptosis }\end{array}$ & [43] & 2014 \\
\hline & & $30 \mu \mathrm{g} / \mathrm{mL}$ & $\mathrm{NA}$ & $48 \mathrm{~h}$ & Time and Dose-dependent & $\mathrm{Ag}$ & Terminalia chebula & Fruit & Not studied & [10] & 2016 \\
\hline & & $72.28 \mu \mathrm{g} / \mathrm{mL}$ & NA & $48 \mathrm{~h}$ & Dose-dependent & $\mathrm{Au}$ & Albizia amara & Leaf & Not studied & [59] & 2017 \\
\hline & & $500 \mu \mathrm{g} / \mathrm{mL}$ & $\mathrm{NA}$ & $48 \mathrm{~h}$ & Dose-dependent & $\mathrm{Ag}$ & Melia dubia & Leaf & Not studied & [51] & 2014 \\
\hline & & $\begin{array}{c}\mathrm{NA}\left(\mathrm{GI}_{50}=\right. \\
61.24 \mu \mathrm{g} / \mathrm{mL})\end{array}$ & NA & $48 \mathrm{~h}$ & Dose-dependent & $\mathrm{Ag}$ & Cymodocea serrulata & Whole plant & Not studied & [61] & 2015 \\
\hline & & NA & $\begin{array}{c}<10 \% \text { cell death in } \\
0.01-20 \mu \mathrm{M}\end{array}$ & $48 \mathrm{~h}$ & Non-cytotoxic & $\mathrm{Au}$ & Genipa americana & Fruit & Not studied & [23] & 2016 \\
\hline & & $18.79 \mu \mathrm{g} / \mathrm{mL}$ & NA & $72 \mathrm{~h}$ & Dose-dependent & $\mathrm{Ag}$ & Aegiceras corniculatum & Leaf & Not studied & [74] & 2017 \\
\hline & $\mathrm{CV}-1$ & NA & $\begin{array}{l}<20 \% \text { cell death in } \\
10 \text { to } 160 \mu \mathrm{g} / \mathrm{mL}\end{array}$ & $24 \mathrm{~h}$ & Non cytotoxic & $\mathrm{Au}$ & Mangifera indica & Peel & NA & [73] & 2014 \\
\hline \multirow[t]{3}{*}{ Adipose } & 3T3-L1 (murine) & $\begin{array}{l}\mathrm{NA}\left(\mathrm{LD}_{20}=\right. \\
10 \mu \mathrm{g} / \mathrm{mL})\end{array}$ & NA & $24 \mathrm{~h}$ & \multirow{3}{*}{$\begin{array}{l}\text { Dose-dependent with } \\
\text { saturation effect }\end{array}$} & $\mathrm{Au}$ & Torreya nucifera & Leaf & \multirow{3}{*}{ Not studied } & \multirow{3}{*}{ [75] } & \multirow{3}{*}{2013} \\
\hline & & NA & $\begin{array}{l}>20 \% \text { cell death } \\
\text { at } 0.1 \mathrm{ng} / \mathrm{mL} \\
\text { and above }\end{array}$ & $24 \mathrm{~h}$ & & $\mathrm{Au}$ & $\begin{array}{l}\text { Cinnamomum } \\
\text { japonicum }\end{array}$ & Leaf & & & \\
\hline & & $\begin{array}{l}\mathrm{NA}\left(\mathrm{LD}_{20}=\right. \\
100 \mathrm{ng} / \mathrm{mL})\end{array}$ & NA & $24 \mathrm{~h}$ & & $\mathrm{Au}$ & Nerium indicum & Leaf & & & \\
\hline Mousefibro & L929 & NA & $\begin{array}{l}<20 \% \text { cell death up } \\
\text { to } 250 \mu \mathrm{g} / \mathrm{mL}\end{array}$ & $24 \mathrm{~h}$ & Non cytotoxic & $\mathrm{Ag}$ & Nyctanthes arbortristis & Flower & NA & [76] & 2015 \\
\hline
\end{tabular}

NA = Not Available 
Table 3. The cytotoxicity of plant-mediated syntheses of metallic nanoparticles on animals (in vivo).

\begin{tabular}{|c|c|c|c|c|c|c|c|c|c|}
\hline Subject & $\mathrm{IC}_{50}$ & Toxicity & Exposure Duration & Response Relationship & Metallic Nanoparticle & Plant & Plant Part & Ref. & Year \\
\hline \multirow{2}{*}{$\begin{array}{l}\text { Adult Zebrafish } \\
\text { (Danio rerio) }\end{array}$} & $142.2 \mathrm{ng} / \mathrm{mL}$ & $\begin{array}{l}\text { Aggressive behaviours and jerky movements } \\
\text { after } 6 \mathrm{~h} \text { of treatment prior to mortality; } 100 \% \\
\text { mortality at } 331.8 \mathrm{ng} / \mathrm{mL}(48 \mathrm{~h}) ; 100 \% \text { mortality } \\
\text { at } 284.4 \mathrm{ng} / \mathrm{mL}(96 \mathrm{~h})\end{array}$ & $\begin{array}{c}96 \mathrm{~h} \\
\text { (Single dose) }\end{array}$ & Dose-dependent & \multirow{2}{*}{$\mathrm{Ag}$} & \multirow{2}{*}{ Malva crispa } & \multirow{2}{*}{ Leaf } & \multirow{2}{*}{ [77] } & \multirow{2}{*}{201} \\
\hline & Dose used $=71.1 \mathrm{ng} / \mathrm{mL}$ & $\begin{array}{l}\text { Gill tissue cell membrane damage; irregular cell } \\
\text { outlines and complete disruption of gill cells; } \\
\text { evidence of genotoxicity in peripheral blood } \\
\text { erythrocytes for AgNP exposed zebrafish }\end{array}$ & $\begin{array}{c}14 \text { days } \\
\text { (given once daily) }\end{array}$ & NA & & & & & \\
\hline
\end{tabular}




\subsection{Safety of Plant-Mediated Synthesis of Metallic Nanoparticles}

A high therapeutic index indicates a larger safety margin. In human breast cancer (MCF-7) cells, Cassia fistula and Melia dubia-derived silver nanoparticles appeared to be the safest, with therapeutic index values of 9.23 and 16.03 after exposure for 24 and $48 \mathrm{~h}$, respectively. However, both studies compared the cytotoxicity potency against animal cells (African green monkey kidney (Vero) cells) instead of normal human cells. In MCF-7 cells, the silver nanoparticles synthesised from Annona squamosa and Oleo europaea (Olive) had therapeutic index values of $<2$ when their cytotoxicity was compared with normal human cells.

In human cervical cancer (HeLa) cells, all plant-mediated synthesis of metallic nanoparticles had a therapeutic index of $\leq 2.5$. Melia azedarach-derived silver nanoparticles had the highest therapeutic index compared to other plants. In addition, when the therapeutic index of cytotoxicity of these nanoparticles was compared to a cytotoxic drug, 5-fluorouracil (5-FU), on the same cancer cells and normal cells, the plant-synthesised metallic nanoparticles were safer than 5-FU [62].

In human colon cancer (HT29) cells, Abutilon indicum-derived gold nanoparticles had a therapeutic index of 4.76 and 5 after exposure of 24 and $48 \mathrm{~h}$, respectively. Both Indoneesiella echioides-derived and Gossypium hirsutum (Cotton)-derived silver nanoparticles were equally safe, having a therapeutic index of 2 when tested on human epithelial lung carcinoma (A549) cells and human breast epithelial (HBL100) cells over $48 \mathrm{~h}$ of exposure. Butea monosperma-derived silver nanoparticles had a therapeutic index of 3.77 when tested over $24 \mathrm{~h}$ on both human myeloid leukaemia (KG-1A) cells and human peripheral blood mononuclear cells (PBMC). In summary, the metallic nanoparticles synthesised from Abutilon inducum, Butea monosperma, Gossypium hirsutum, Indoneesiella echioides, and Melia azedarach were acceptably safe, as their therapeutic index values were $\geq 2.0$ when tested on both cancer cells and normal human cells.

\subsection{Size and Cytotoxicity}

The average size of plant-mediated synthesis of metallic nanoparticles that showed cytotoxicity as fast as $4 \mathrm{~h}$ up to 14 days ranged from 20 to $355 \mathrm{~nm}$, although those larger than $100 \mathrm{~nm}$ were less commonly synthesised. The average size of the metal plant-synthesised nanoparticles (gold and silver) plotted against $\mathrm{LD}_{50}$ or $\mathrm{IC}_{50}$ at $24 \mathrm{~h}$ exposure (Figure 1) and at $48 \mathrm{~h}$ (Figure 2) in vitro are shown.

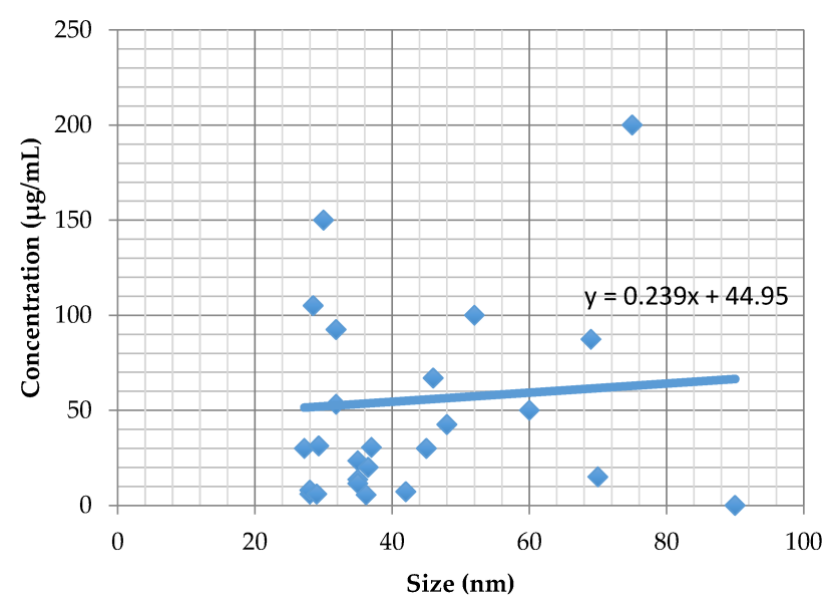

Figure 1. The correlation between the average size of the plant-mediated syntheses of metallic nanoparticles and cytotoxicity at $24 \mathrm{~h}$ of exposure. Plant metallic nanoparticles; — Trendline.

Both figures show that the cytotoxicity is inversely proportional to size; smaller nanoparticles have smaller $\mathrm{LD}_{50}$ or $\mathrm{IC}_{50}$ values, which translates to stronger cytotoxicity. This finding is in agreement with a previous study which showed that chemically derived smaller sized gold nanoparticles were highly toxic compared to those of larger sizes, irrespective of the cancer cell types tested [78]. 


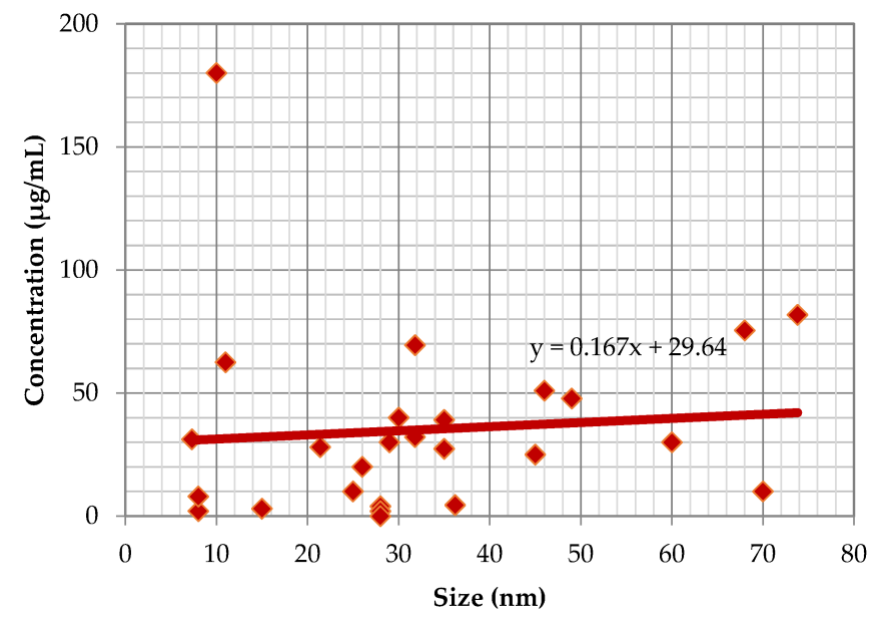

Figure 2. The correlation between the average size of the plant-mediated syntheses of metallic nanoparticles and cytotoxicity at $48 \mathrm{~h}$ of exposure. Plant metallic nanoparticles; — Trendline.

\subsection{Morphology and Cytotoxicity}

Figure 3 shows a comparison of the morphological effect of the plant-mediated syntheses of metallic nanoparticles on their cytotoxicity.

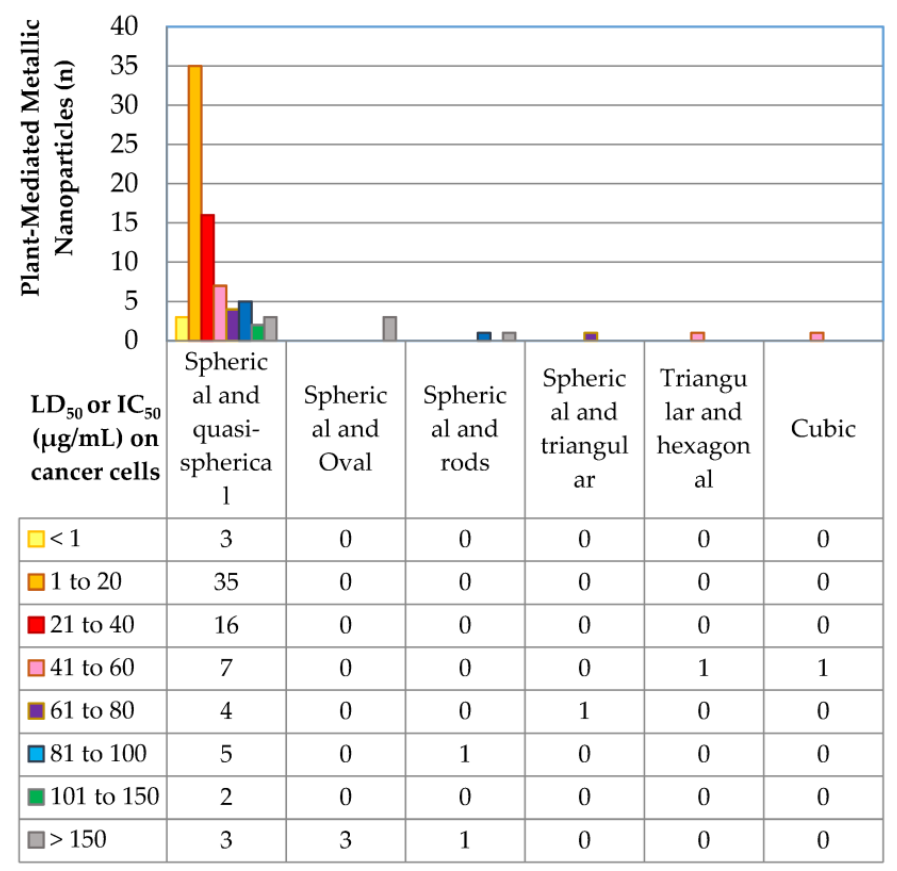

Figure 3. The correlation between plant-mediated syntheses of metallic nanoparticle morphology and cytotoxicity.

Plant-synthesised metallic nanoparticles vary in shape and can be rods-shaped, spherical, quasi-spherical, oval, triangular, hexagonal, and cubic. In several articles, V-shaped, Y-shaped, and flat plate shaped nanoparticles were described, but those studies were not included for reasons mentioned previously. The plant-mediated syntheses of metallic nanoparticles were predominantly spherical in shape. Those of spherical and quasi-spherical shape had a wide range of cytotoxicity potency, with $\mathrm{LD}_{50}$ values ranging from $<1 \mu \mathrm{g} / \mathrm{mL}$ to $>150 \mu \mathrm{g} / \mathrm{mL}$. Spherical and quasi-spherical nanoparticles appeared most often, with $\mathrm{LD}_{50}$ of $1-20 \mu \mathrm{g} / \mathrm{mL}$ being the mode of the populations, followed by $21-40$ 
and 41-60 $\mu \mathrm{g} / \mathrm{mL}$. Triangular, hexagonal, and rod-shaped nanoparticles were less common and had $\mathrm{LD}_{50}$ values of $>41 \mu \mathrm{g} / \mathrm{mL}$ (that is, higher than the minimum value of spherical and quasi-spherical shaped nanoparticles).

\section{Discussion}

This systematic review provides a comparison among the studies and more detailed information to explain the complex issues involved in the pursuit of suitable plant-mediated synthesis of metallic nanoparticles for their potential use as anti-cancer agents. The review also provides an overview of $\mathrm{LD}_{50}$ and/or cell death of various cancer cells exposed to the synthesised nanoparticles and the extent of agreement or disagreement among the studies regarding their cytotoxicity. Clear documentation of the content of the selected articles is given, which will enable other researchers to assess the validity of the findings. Furthermore, a better understanding of the overall picture of the plant-mediated syntheses of metallic nanoparticle cytotoxicity can be achieved from this review.

Most plant-synthesised metallic nanoparticles discovered to date have a narrow range of doses for their therapeutic index, even when it is regarded as acceptable for oncology indications. Drugs with a narrow therapeutic index are those drugs for which small differences in dose or blood concentration may lead to serious therapeutic failures and/or adverse drug reactions that are life-threatening or result in persistent or significant disability or incapacity [79]. Metallic nanoparticles synthesised by Abutilon inducum, Butea monosperma, Gossypium hirsutum, Indoneesiella echioides, and Melia azedarach are among the potential anti-cancer agents identified in this review as having an acceptable therapeutic index as a safety marker. Knowing the therapeutic index of a plant-mediated synthesis of metallic nanoparticles can aid in the careful selection of a suitable new entity treatment modality that has a good safety profile for patients or can be used to test subjects before proceeding to animal studies and clinical trials. From the longer-term perspective, this can help reduce the number of expensive research failures in the late stage of clinical trials [80]. However, the therapeutic index results obtained in this review are only preliminary and they could change and be refined as drug development studies progress from in vitro to animal safety to human safety.

Nanoparticles can be taken up into cells through non-specific cellular uptake and via cell functions such as adhesion, cytoskeleton organisation, migration, proliferation, and apoptosis, and these processes may be influenced by nanoparticle shape [81]. Identifying the size and morphology of the plant-mediated syntheses of metallic nanoparticles is important because it will allow for the engineering of nanoparticles with proper shapes and sizes for the maximal accumulation in a malignant tumour. Although nanoparticle size and morphology have significant effects on cytotoxicity potency, other parameters are important as well, such as surface properties, aggregation/agglomeration state, solubility, and surface properties; attached functional groups, surface area, and surface charges also play important roles in influencing the resultant pharmacokinetics and pharmacodynamics of nanoparticles $[22,82,83]$.

The studies analysed in this review included cytotoxicity assays of plant-mediated syntheses of metallic nanoparticles using different cell lines, exposure time lengths, and a wide range of concentrations. This variation made it difficult to make direct comparisons among the available studies. However, the existing data were extracted and the general trends in the pool were evaluated. The results indicate that, ideally designed research studies of plant-mediated syntheses of metallic nanoparticles are lacking. Many of the selected studies compared cytotoxicity of nanoparticles against human cancer cells and non-human normal cells, thus, the therapeutic index could differ when proceeding with clinical trials. Some in vivo studies poorly described exposure conditions such as route of entry and dosing regimen or interval. Additionally, different studies used different standards to measure exposures and outcomes, which might have caused variation in the results displayed. Thus, there is a need for better constructed, suitable, and concrete research that can provide stronger evidence for the efficacy and safety of plant-mediated synthesis of metallic nanoparticles as cytotoxic agents. 


\section{Materials and Methods}

\subsection{Search Strategy}

The literature search was executed on full-text electronic databases such as Science Direct, PubMed, and Springer Link. The general search engine Google Scholar and the academic social networking site ResearchGate were also used to obtain research articles. Biosynthesis, plant synthesis, plant-mediated, metallic nanoparticle, cytotoxicity, and anti-cancer were the keywords used for the literature search. A reviewer independently screened the titles and abstracts of the citations and retrieved the relevant articles from the identified full-text electronic journal databases.

With the objective of complementing the database searches, non-automated manual searches of the references within the selected articles were conducted. After the search strategy was applied, two examiners reviewed the screened the research titles and abstracts. The full text of each identified study was retrieved by one author. Documentation of the whole search process was carried out to ensure transparency, replicability, and feasibility to reanalyse (Figure 4).

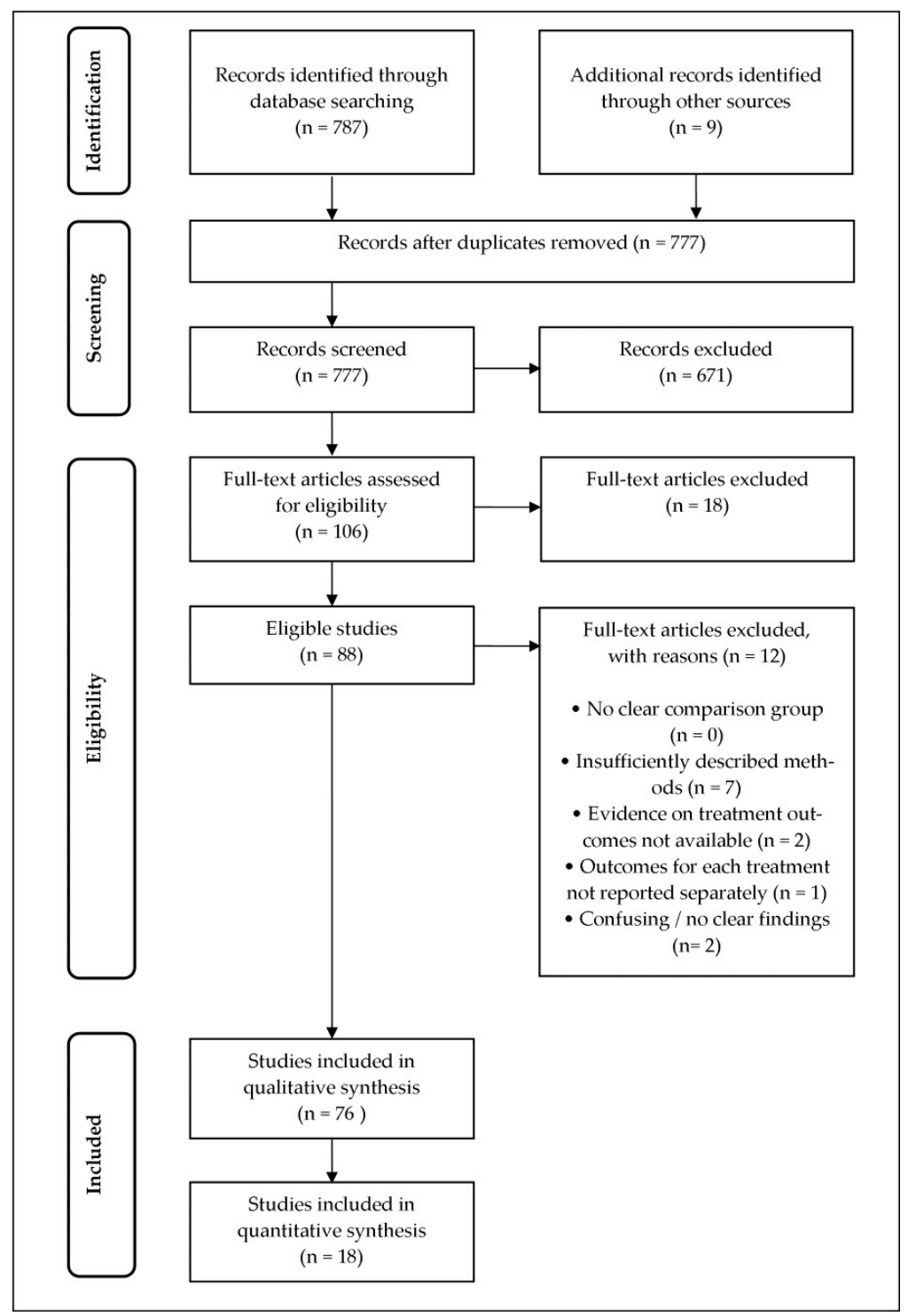

Figure 4. The flow chart of the systematic review information of screening and choosing articles. 


\subsection{Study Selection}

All types of research (in vitro, in vivo, and ex vivo studies) and reviews that met the inclusion criteria were included in the study regardless of whether the results were positive, negative, or null to diminish selection bias. Preclinical and clinical trials were not included because none had been conducted by the date of this analysis. The inclusion criteria were metallic nanoparticles; gold ( $\mathrm{Au}$ ), silver (Ag); biologically synthesised using plants; recently published studies conducted between 2006 and 2017 (including in-press articles); and all types of studies (in vitro, in vivo, ex vivo, and review). Studies with any of the following criteria were excluded from this study: (1) metallic nanoparticles derived from non-vascular plants (fungus, seaweeds, mushrooms); (2) metallic nanoparticles derived from undefined plants (specific pure compound from an unknown plant used in the biosynthesis); (3) combined synthesis of metallic nanoparticle with chemical or physical methods; (4) combined metallic nanoparticles; (5) studies without available data; and (6) articles that were written in a language other than English.

The titles and abstracts for 796 articles were screened, but only 88 articles were related to the research question. For the 88 potentially eligible articles, the following criteria were established to assess the quality of the study: (1) clearly defined control/comparison group; (2) duration of exposure clearly stated; (3) method conducted at $37{ }^{\circ} \mathrm{C}$ to mimic the human body temperature; (4) clearly defined and measured outcomes (median lethal dose $\left(\mathrm{LD}_{50}\right)$, median inhibitory concentration $\left(\mathrm{IC}_{50}\right)$, median growth inhibitory concentration $\left(\mathrm{GI}_{50}\right)$, cell viability, cell death); (5) ethical standards carried out and maintained, if relevant; (6) reliable method used to measure outcomes; (7) multiple measurements of outcome conducted (at least in triplicate); (8) actual data or evidence available on all treatment outcomes; (9) outcomes reported separately for each treatment; (10) clear statement of findings; and (11) appropriate statistical analyses used.

The above study criteria were used with the goal of eliminating attrition biases due to the incomplete reporting of data for each outcome as well as reporting biases from selective reporting of positive outcomes. The following appraisal guidelines were used when developing the study criteria: (1) Preferred Reporting Items for Systematic Review and Meta-Analysis Protocols (PRISMA-P) 2015 checklist [84] and (2) Risk of Bias Assessment Tool for Non-randomised Studies (RoBANS) [85]. Figure 1 shows the methodology used in this study to identify eligible articles.

Data from the selected studies were extracted by one independent author, and that author's results were counterchecked by two examiners. Descriptions of the evidence were presented in tabular format. The primary outcome measures were $\mathrm{LD}_{50}$ and/or $\mathrm{IC}_{50}$ for cytotoxicity and therapeutic index for safety. The therapeutic index for the plant-mediated synthesis of metallic nanoparticles was calculated for studies that conducted cytotoxicity testing on both cancer and normal cell types. The therapeutic index is often used to measure the safety of a drug for a particular treatment. It is defined as the ratio of the $\mathrm{LD}_{50}$ to the median effective dose $\left(\mathrm{ED}_{50}\right)$ (Equation (1)) [86].

$$
\text { Therapeutic Index }(\mathrm{TI})=\frac{\text { Median Lethal Dose }(\text { LD50) }}{\text { Median Effective Dose (EC50) }}
$$

$\mathrm{LD}_{50}$ is the dose required to kill $50 \%$ of the tested population after a specified test duration, and $\mathrm{ED}_{50}$ is the dose required to achieve the desired outcome or response in $50 \%$ of the tested population. Based on the availability of a reasonable therapeutic index value, the potential plant-mediated syntheses of metallic nanoparticles with the most promise as anticancer agents were selected. The correlation between the average size/morphology of plant-synthesised metallic nanoparticles and cytotoxicity potency was also analysed.

\section{Conclusions}

With respect to the above-mentioned results and discussion, it is concluded that silver plant-mediated nanoparticles have higher cytotoxicity compared to gold, irrespective of the cell 
types used. The size and shape determined the resultant cytotoxicity of the plant-mediated synthesis of metallic nanoparticles. Most of the nanoparticles have a narrow therapeutic index despite the acceptance of oncology indications. Metallic nanoparticles synthesised from Abutilon inducum, Butea monosperma, Gossypium hirsutum, Indoneesiella echioides, and Melia azedarach are among the potential anti-cancer agents with an acceptable therapeutic index as the safety marker. Future studies should focus on the pharmacological/toxicological and pharmacokinetic/toxicokinetic actions of the potential anti-cancer agents.

Author Contributions: V.L. and N.A.H. designed this review; V.L., M.R.R. and N.Y. supervised the activity planning and execution; N.A.H., N.N.M.Z. and H.I.C. assembled and analysed the input data; V.L. and M.R.R. validated the input and output data; N.A.H., W.H.T. and V.L. wrote and proofread the manuscript. All authors commented critically on the manuscript and contributed text to the final version.

Acknowledgments: The authors would like to thank Universiti Sains Malaysia (USM) and the Ministry of Higher Education, Malaysia for funding support from Research University grant (RU, 1001/CIPPT/811318) and Fundamental Research Grant Scheme (FRGS, 203/CIPPT/6711382). The authors gratefully acknowledge Postgraduate Development Fund from the Institute of Postgraduate Studies, USM.

Conflicts of Interest: The authors declare no conflict of interest. The founding sponsors had no role in the design of the study; in the collection, analyses, or interpretation of data; in the writing of the manuscript, and in the decision to publish the results.

\section{References}

1. Hay, S.I.; Jayaraman, S.P.; Truelsen, T.; Sorensen, R.J.; Millear, A.; Giussani, G.; Beghi, E. GBD 2015 Disease and Injury Incidence and Prevalence Collaborators. Global, regional, and national incidence, prevalence, and years lived with disability for 310 diseases and injuries, 1990-2015: A systematic analysis for the Global Burden of Disease Study 2015. Lancet 2017, 389, 1545-1602.

2. Thakkar, K.N.; Mhatre, S.S.; Parikh, R.Y. Biological synthesis of metallic nanoparticles. Nanomed. Nanotechnol. Biol. Med. 2010, 6, 257-262. [CrossRef] [PubMed]

3. Ahmad, N.; Sharma, S.; Alam, M.K.; Singh, V.; Shamsi, S.; Mehta, B.; Fatma, A. Rapid synthesis of silver nanoparticles using dried medicinal plant of basil. Colloids Surf. B Biointerfaces 2010, 81, 81-86. [CrossRef] [PubMed]

4. Mohanpuria, P.; Rana, N.K.; Yadav, S.K. Biosynthesis of nanoparticles: Technological concepts and future applications. J. Nanopart. Res. 2008, 10, 507-517. [CrossRef]

5. Kuppurangan, G.; Karuppasamy, B.; Nagarajan, K.; Sekar, R.K.; Viswaprakash, N.; Ramasamy, T. Biogenic synthesis and spectroscopic characterization of silver nanoparticles using leaf extract of Indoneesiella echioides: In vitro assessment on antioxidant, antimicrobial and cytotoxicity potential. Appl. Nanosci. 2016, 6, 973-982. [CrossRef]

6. Selvarani, S. Anti-Cancer Activity of Silver Nanoparticle Synthesized from Stem Extract of Ocimum Kilimandscharicum against Hep-G2, Liver Cancer Cell Line. J. Nanotechnol. Nanosci. 2015, 1, 100103.

7. Mata, R.; Nakkala, J.R.; Sadras, S.R. Catalytic and biological activities of green silver nanoparticles synthesized from Plumeria alba (frangipani) flower extract. Mater. Sci. Eng. C 2015, 51, 216-225. [CrossRef] [PubMed]

8. Mishra, P.; Ray, S.; Sinha, S.; Das, B.; Khan, M.I.; Behera, S.K.; Yun, S.-I.; Tripathy, S.K.; Mishra, A. Facile bio-synthesis of gold nanoparticles by using extract of Hibiscus sabdariffa and evaluation of its cytotoxicity against U87 glioblastoma cells under hyperglycemic condition. Biochem. Eng. J. 2016, 105, $264-272$.

9. Dipankar, C.; Murugan, S. The green synthesis, characterization and evaluation of the biological activities of silver nanoparticles synthesized from Iresine herbstii leaf aqueous extracts. Colloids Surf. B Biointerfaces 2012, 98, 112-119. [CrossRef] [PubMed]

10. Bupesh, G.; Manikandan, E.; Thanigaiarul, K.; Magesh, S.; Senthilkumar, V.; Tamilarasan, S.; Pandian, K.; Gurib-Fakim, A.; Maaza, M. Enhanced antibacterial, anticancer activity from Terminalia chebula medicinal plant rapid extract by phytosynthesis of silver nanoparticles core-shell structures. J. Nanomed. Nanotechnol. 2016, 7, 2 . 
11. Mittal, A.K.; Tripathy, D.; Choudhary, A.; Aili, P.K.; Chatterjee, A.; Singh, I.P.; Banerjee, U.C. Bio-synthesis of silver nanoparticles using Potentilla fulgens Wall. ex Hook. and its therapeutic evaluation as anticancer and antimicrobial agent. Mater. Sci. Eng. C 2015, 53, 120-127.

12. Mukundan, D.; Mohankumar, R.; Vasanthakumari, R. Green Synthesis of Silver Nanoparticles Using Leaves Extract of Bauhinia Tomentosa Linn and its Invitro Anticancer Potential. Mater. Today Proc. 2015, 2, 4309-4316. [CrossRef]

13. Spector, R. Progress in the search for ideal drugs. Pharmacology 2002, 64, 1-7. [CrossRef] [PubMed]

14. Parveen, A.; Rao, S. Cytotoxicity and genotoxicity of biosynthesized gold and silver nanoparticles on human cancer cell lines. J. Clust. Sci. 2015, 26, 775-788. [CrossRef]

15. Nazeema, T.H.; Sugannya, P.K. Synthesis and characterization of silver nanoparticle from two medicinal plants and its anticancer property. Int. J. Res. Eng. Technol. 2014, 2, 49-56.

16. Valodkar, M.; Jadeja, R.N.; Thounaojam, M.C.; Devkar, R.V.; Thakore, S. In vitro toxicity study of plant latex capped silver nanoparticles in human lung carcinoma cells. Mater. Sci. Eng. C 2011, 31, 1723-1728. [CrossRef]

17. Manju, S.; Malaikozhundan, B.; Vijayakumar, S.; Shanthi, S.; Jaishabanu, A.; Ekambaram, P.; Vaseeharan, B. Antibacterial, antibiofilm and cytotoxic effects of Nigella sativa essential oil coated gold nanoparticles. Microb. Pathog. 2016, 91, 129-135. [CrossRef] [PubMed]

18. Nakkala, J.R.; Mata, R.; Gupta, A.K.; Sadras, S.R. Biological activities of green silver nanoparticles synthesized with Acorous calamus rhizome extract. Eur. J. Med. Chem. 2014, 85, 784-794. [CrossRef] [PubMed]

19. Venkatesan, B.; Subramanian, V.; Tumala, A.; Vellaichamy, E. Rapid synthesis of biocompatible silver nanoparticles using aqueous extract of Rosa damascena petals and evaluation of their anticancer activity. Asian Pac. J. Trop. Med. 2014, 7, S294-S300. [CrossRef]

20. Sankar, R.; Karthik, A.; Prabu, A.; Karthik, S.; Shivashangari, K.S.; Ravikumar, V. Origanum vulgare mediated biosynthesis of silver nanoparticles for its antibacterial and anticancer activity. Colloids Surf. B Biointerfaces 2013, 108, 80-84. [CrossRef] [PubMed]

21. Kanipandian, N.; Thirumurugan, R. A feasible approach to phyto-mediated synthesis of silver nanoparticles using industrial crop Gossypium hirsutum (cotton) extract as stabilizing agent and assessment of its in vitro biomedical potential. Ind. Crops Prod. 2014, 55, 1-10. [CrossRef]

22. Sathishkumar, M.; Pavagadhi, S.; Mahadevan, A.; Balasubramanian, R. Biosynthesis of gold nanoparticles and related cytotoxicity evaluation using A549 cells. Ecotoxicol. Environ. Saf. 2015, 114, 232-240. [CrossRef] [PubMed]

23. Kumar, B.; Smita, K.; Cumbal, L.; Camacho, J.; Hernández-Gallegos, E.; de Guadalupe Chávez-López, M.; Grijalva, M.; Andrade, K. One pot phytosynthesis of gold nanoparticles using Genipa americana fruit extract and its biological applications. Mater. Sci. Eng. C 2016, 62, 725-731. [CrossRef] [PubMed]

24. Ashokkumar, T.; Prabhu, D.; Geetha, R.; Govindaraju, K.; Manikandan, R.; Arulvasu, C.; Singaravelu, G. Apoptosis in liver cancer (HepG2) cells induced by functionalized gold nanoparticles. Colloids Surf. B Biointerfaces 2014, 123, 549-556. [CrossRef] [PubMed]

25. Inbathamizh, L.; Ponnu, T.M.; Mary, E.J. In vitro evaluation of antioxidant and anticancer potential of Morinda pubescens synthesized silver nanoparticles. J. Pharm. Res. 2013, 6, 32-38. [CrossRef]

26. Patil, M.P.; Ngabire, D.; Thi, H.H.P.; Kim, M.-D.; Kim, G.-D. Eco-friendly synthesis of gold nanoparticles and evaluation of their cytotoxic activity on cancer cells. J. Clust. Sci. 2016, 28, 119-132. [CrossRef]

27. Durai, P.; Chinnasamy, A.; Gajendran, B.; Ramar, M.; Pappu, S.; Kasivelu, G.; Thirunavukkarasu, A. Synthesis and characterization of silver nanoparticles using crystal compound of sodium para-hydroxybenzoate tetrahydrate isolated from Vitex negundo L leaves and its apoptotic effect on human colon cancer cell lines. Eur. J. Med. Chem. 2014, 84, 90-99. [CrossRef] [PubMed]

28. Prabhu, D.; Arulvasu, C.; Babu, G.; Manikandan, R.; Srinivasan, P. Biologically synthesized green silver nanoparticles from leaf extract of Vitex negundo L. induce growth-inhibitory effect on human colon cancer cell line HCT15. Process Biochem. 2013, 48, 317-324.

29. Kuppusamy, P.; Ichwan, S.J.; Al-Zikri, P.N.H.; Suriyah, W.H.; Soundharrajan, I.; Govindan, N.; Maniam, G.P.; Yusoff, M.M. In vitro anticancer activity of Au, Ag nanoparticles synthesized using Commelina nudiflora L. aqueous extract against HCT-116 colon cancer cells. Biol. Trace Elem. Res. 2016, 173, 297-305. [PubMed]

30. Sengani, M.; Devi Rajeswari, V. Cytotoxicity and apoptotic effect of biogenic silver nanoparticles on human colorectal cell line HT-29. Res. J. Biotechnol. 2016, 11, 9. 
31. Ghozali, S.; Vuanghao, L.; Ahmad, N. Biosynthesis and Characterization of Silver Nanoparticles using Catharanthus roseus Leaf Extract and its Proliferative Effects on Cancer Cell Lines. J. Nanomed. Nanotechnol. 2015, 6, 1 .

32. Mata, R.; Nakkala, J.R.; Sadras, S.R. Polyphenol stabilized colloidal gold nanoparticles from Abutilon indicum leaf extract induce apoptosis in HT-29 colon cancer cells. Colloids Surf. B Biointerfaces 2016, 143, 499-510. [CrossRef] [PubMed]

33. Premasudha, P.; Venkataramana, M.; Abirami, M.; Vanathi, P.; Krishna, K.; Rajendran, R. Biological synthesis and characterization of silver nanoparticles using Eclipta alba leaf extract and evaluation of its cytotoxic and antimicrobial potential. Bull. Mater. Sci. 2015, 38, 965-973. [CrossRef]

34. Mata, R.; Nakkala, J.R.; Sadras, S.R. Biogenic silver nanoparticles from Abutilon indicum: Their antioxidant, antibacterial and cytotoxic effects in vitro. Colloids Surf. B Biointerfaces 2015, 128, 276-286. [CrossRef] [PubMed]

35. Potara, M.; Bawaskar, M.; Simon, T.; Gaikwad, S.; Licarete, E.; Ingle, A.; Banciu, M.; Vulpoi, A.; Astilean, S.; Rai, M. Biosynthesized silver nanoparticles performing as biogenic SERS-nanotags for investigation of C26 colon carcinoma cells. Colloids Surf. B Biointerfaces 2015, 133, 296-303. [CrossRef] [PubMed]

36. Gopinath, V.; Priyadarshini, S.; MubarakAli, D.; Loke, M.F.; Thajuddin, N.; Alharbi, N.S.; Yadavalli, T.; Alagiri, M.; Vadivelu, J. Anti-Helicobacter pylori, cytotoxicity and catalytic activity of biosynthesized gold nanoparticles: Multifaceted application. Arabian J. Chem. 2016. [CrossRef]

37. Rashidipour, M.; Heydari, R. Biosynthesis of silver nanoparticles using extract of olive leaf: Synthesis and in vitro cytotoxic effect on MCF-7 cells. J. Nanostruct. Chem. 2014, 4, 1-6. [CrossRef]

38. Sathishkumar, G.; Gobinath, C.; Wilson, A.; Sivaramakrishnan, S. Dendrophthoe falcata (Lf) Ettingsh (Neem mistletoe): A potent bioresource to fabricate silver nanoparticles for anticancer effect against human breast cancer cells (MCF-7). Spectrochim. Acta Part A 2014, 128, 285-290. [CrossRef] [PubMed]

39. Reddy, N.J.; Vali, D.N.; Rani, M.; Rani, S.S. Evaluation of antioxidant, antibacterial and cytotoxic effects of green synthesized silver nanoparticles by Piper longum fruit. Mater. Sci. Eng. C 2014, 34, 115-122. [CrossRef] [PubMed]

40. Farah, M.A.; Ali, M.A.; Chen, S.M.; Li, Y.; Al-Hemaid, F.M.; Abou-Tarboush, F.M.; Al-Anazi, K.M.; Lee, J. Silver nanoparticles synthesized from Adenium obesum leaf extract induced DNA damage, apoptosis and autophagy via generation of reactive oxygen species. Colloids Surf. B Biointerfaces 2016, 141, 158-169. [CrossRef] [PubMed]

41. Remya, R.; Rajasree, S.R.; Aranganathan, L.; Suman, T. An investigation on cytotoxic effect of bioactive AgNPs synthesized using Cassia fistula flower extract on breast cancer cell MCF-7. Biotechnol. Rep. 2015, 8, 110-115. [CrossRef] [PubMed]

42. Suganya, K.U.; Govindaraju, K.; Kumar, V.G.; Karthick, V.; Parthasarathy, K. Pectin mediated gold nanoparticles induces apoptosis in mammary adenocarcinoma cell lines. Int. J. Biol. Macromol. 2016, 93, 1030-1040. [CrossRef] [PubMed]

43. Gajendran, B.; Chinnasamy, A.; Durai, P.; Raman, J.; Ramar, M. Biosynthesis and characterization of silver nanoparticles from Datura inoxia and its apoptotic effect on human breast cancer cell line MCF7. Mater. Lett. 2014, 122, 98-102. [CrossRef]

44. Jeyaraj, M.; Sathishkumar, G.; Sivanandhan, G.; MubarakAli, D.; Rajesh, M.; Arun, R.; Kapildev, G.; Manickavasagam, M.; Thajuddin, N.; Premkumar, K.; et al. Biogenic silver nanoparticles for cancer treatment: An experimental report. Colloids Surf. B Biointerfaces 2013, 106, 86-92. [CrossRef] [PubMed]

45. Ramar, M.; Manikandan, B.; Marimuthu, P.N.; Raman, T.; Mahalingam, A.; Subramanian, P.; Karthick, S.; Munusamy, A. Synthesis of silver nanoparticles using Solanum trilobatum fruits extract and its antibacterial, cytotoxic activity against human breast cancer cell line MCF 7. Spectrochim. Acta Part A 2015, 140, 223-228. [CrossRef] [PubMed]

46. Sathishkumar, P.; Preethi, J.; Vijayan, R.; Yusoff, A.R.M.; Ameen, F.; Suresh, S.; Balagurunathan, R.; Palvannan, T. Anti-acne, anti-dandruff and anti-breast cancer efficacy of green synthesised silver nanoparticles using Coriandrum sativum leaf extract. J. Photochem. Photobiol. B Biol. 2016, 163, 69-76. [CrossRef] [PubMed]

47. Sathishkumar, P.; Vennila, K.; Jayakumar, R.; Yusoff, A.R.M.; Hadibarata, T.; Palvannan, T. Phyto-synthesis of silver nanoparticles using Alternanthera tenella leaf extract: An effective inhibitor for the migration of human breast adenocarcinoma (MCF-7) cells. Bioprocess Biosyst. Eng. 2016, 39, 651-659. [CrossRef] [PubMed] 
48. Vivek, R.; Thangam, R.; Muthuchelian, K.; Gunasekaran, P.; Kaveri, K.; Kannan, S. Green biosynthesis of silver nanoparticles from Annona squamosa leaf extract and its in vitro cytotoxic effect on MCF-7 cells. Process Biochem. 2012, 47, 2405-2410. [CrossRef]

49. Priya, M.K.; Iyer, P.R. Anticancer studies of the synthesized gold nanoparticles against MCF 7 breast cancer cell lines. Appl. Nanosci. 2015, 5, 443-448. [CrossRef]

50. Lokina, S.; Stephen, A.; Kaviyarasan, V.; Arulvasu, C.; Narayanan, V. Cytotoxicity and antimicrobial activities of green synthesized silver nanoparticles. Eur. J. Med. Chem. 2014, 76, 256-263. [CrossRef] [PubMed]

51. Kathiravan, V.; Ravi, S.; Ashokkumar, S. Synthesis of silver nanoparticles from Melia dubia leaf extract and their in vitro anticancer activity. Spectrochim. Acta Part A 2014, 130, 116-121. [CrossRef] [PubMed]

52. Balasubramani, G.; Ramkumar, R.; Krishnaveni, N.; Pazhanimuthu, A.; Natarajan, T.; Sowmiya, R.; Perumal, P. Structural characterization, antioxidant and anticancer properties of gold nanoparticles synthesized from leaf extract (decoction) of Antigonon leptopus Hook. Arn. J. Trace Elem. Med. Biol. 2015, 30, 83-89. [PubMed]

53. Shittu, O.K.; Stephen, D.I. In vitro Membranous activity of Biosynthesized Gold Nanoparticle from Aqueous Leave Extract of Nelsonia canescens. Eur. J. Med. Plants 2016, 15, 1-8. [CrossRef]

54. Aadil, K.R.; Barapatre, A.; Meena, A.S.; Jha, H. Hydrogen peroxide sensing and cytotoxicity activity of Acacia lignin stabilized silver nanoparticles. Int. J. Biol. Macromol. 2016, 82, 39-47. [CrossRef] [PubMed]

55. Rajendran, R.; Ganesan, N.; Balu, S.K.; Alagar, S.; Thandavamoorthy, P.; Thiruvengadam, D. Green synthesis, characterization, antimicrobial and cytotoxic effects of silver nanoparticles using Origanum heracleoticum $\mathrm{L}$. Leaf extract. Int. J. Pharm. Pharm. Sci. 2015, 7, 288-293.

56. Jeyaraj, M.; Arun, R.; Sathishkumar, G.; MubarakAli, D.; Rajesh, M.; Sivanandhan, G.; Kapildev, G.; Manickavasagam, M.; Thajuddin, N.; Ganapathi, A. An evidence on G2/M arrest, DNA damage and caspase mediated apoptotic effect of biosynthesized gold nanoparticles on human cervical carcinoma cells (HeLa). Mater. Res. Bull. 2014, 52, 15-24. [CrossRef]

57. Mahendran, G.; Kumari, B.R. Biological activities of silver nanoparticles from Nothapodytes nimmoniana (Graham) Mabb. fruit extracts. Food Sci. Hum. Wellness 2016, 5, 207-218. [CrossRef]

58. Rajkuberan, C.; Prabukumar, S.; Sathishkumar, G.; Wilson, A.; Ravindran, K.; Sivaramakrishnan, S. Facile synthesis of silver nanoparticles using Euphorbia antiquorum L. latex extract and evaluation of their biomedical perspectives as anticancer agents. J. Saudi Chem. Soc. 2016, 21, 911-919.

59. Balasubramani, G.; Ramkumar, R.; Raja, R.K.; Aiswarya, D.; Rajthilak, C.; Perumal, P. Albizia amara Roxb. Mediated Gold Nanoparticles and Evaluation of Their Antioxidant, Antibacterial and Cytotoxic Properties. J. Clust. Sci. 2017, 28, 259-275.

60. Lokina, S.; Suresh, R.; Giribabu, K.; Stephen, A.; Sundaram, R.L.; Narayanan, V. Spectroscopic investigations, antimicrobial, and cytotoxic activity of green synthesized gold nanoparticles. Spectrochim. Acta Part A 2014, 129, 484-490. [CrossRef] [PubMed]

61. Chanthini, A.B.; Balasubramani, G.; Ramkumar, R.; Sowmiya, R.; Balakumaran, M.D.; Kalaichelvan, P.T.; Perumal, P. Structural characterization, antioxidant and in vitro cytotoxic properties of seagrass, Cymodocea serrulata (R. Br.) Asch. \& Magnus mediated silver nanoparticles. J. Photochem. Photobiol. B Biol. 2015, 153, 145-152.

62. Sukirtha, R.; Priyanka, K.M.; Antony, J.J.; Kamalakkannan, S.; Thangam, R.; Gunasekaran, P.; Krishnan, M.; Achiraman, S. Cytotoxic effect of Green synthesized silver nanoparticles using Melia azedarach against in vitro HeLa cell lines and lymphoma mice model. Process Biochem. 2012, 47, 273-279. [CrossRef]

63. Sulaiman, G.M.; Mohammed, W.H.; Marzoog, T.R.; Al-Amiery, A.A.A.; Kadhum, A.A.H.; Mohamad, A.B. Green synthesis, antimicrobial and cytotoxic effects of silver nanoparticles using Eucalyptus chapmaniana leaves extract. Asian Pac. J. Trop. Biomed. 2013, 3, 58-63. [CrossRef]

64. Geetha, R.; Ashokkumar, T.; Tamilselvan, S.; Govindaraju, K.; Sadiq, M.; Singaravelu, G. Green synthesis of gold nanoparticles and their anticancer activity. Cancer Nanotechnol. 2013, 4, 91. [CrossRef] [PubMed]

65. Mollick, M.M.R.; Rana, D.; Dash, S.K.; Chattopadhyay, S.; Bhowmick, B.; Maity, D.; Mondal, D.; Pattanayak, S.; Roy, S.; Chakraborty, M.; et al. Studies on green synthesized silver nanoparticles using Abelmoschus esculentus (L.) pulp extract having anticancer (in vitro) and antimicrobial applications. Arabian J. Chem. 2015. [CrossRef] 
66. Pattanayak, S.; Mollick, M.M.R.; Maity, D.; Chakraborty, S.; Dash, S.K.; Chattopadhyay, S.; Roy, S.; Chattopadhyay, D.; Chakraborty, M. Butea monosperma bark extract mediated green synthesis of silver nanoparticles: Characterization and biomedical applications. J. Saudi Chem. Soc. 2015. [CrossRef]

67. Nayak, D.; Ashe, S.; Rauta, P.R.; Kumari, M.; Nayak, B. Bark extract mediated green synthesis of silver nanoparticles: Evaluation of antimicrobial activity and antiproliferative response against osteosarcoma. Mater. Sci. Eng. C 2016, 58, 44-52. [CrossRef] [PubMed]

68. Karuppaiya, P.; Satheeshkumar, E.; Chao, W.-T.; Kao, L.-Y.; Chen, E.C.-F.; Tsay, H.-S. Anti-metastatic activity of biologically synthesized gold nanoparticles on human fibrosarcoma cell line HT-1080. Colloids Surf. $B$ Biointerfaces 2013, 110, 163-170. [CrossRef] [PubMed]

69. Rosarin, F.S.; Arulmozhi, V.; Nagarajan, S.; Mirunalini, S. Antiproliferative effect of silver nanoparticles synthesized using amla on Hep2 cell line. Asian Pac. J. Trop. Med. 2013, 6, 1-10. [CrossRef]

70. Jacob, S.J.P.; Finub, J.; Narayanan, A. Synthesis of silver nanoparticles using Piper longum leaf extracts and its cytotoxic activity against Hep-2 cell line. Colloids Surf. B Biointerfaces 2012, 91, 212-214. [CrossRef] [PubMed]

71. Velammal, S.P.; Devi, T.A.; Amaladhas, T.P. Antioxidant, antimicrobial and cytotoxic activities of silver and gold nanoparticles synthesized using Plumbago zeylanica bark. J. Nanostruct. Chem. 2016, 6, 247-260. [CrossRef]

72. Chowdhury, N.R.; Macgregor-Ramiasa, M.; Zilm, P.; Majewski, P.; Vasilev, K. 'Chocolate' silver nanoparticles: Synthesis, antibacterial activity and cytotoxicity. J. Colloid Interface Sci. 2016, 482, 151-158. [CrossRef] [PubMed]

73. Yang, N.; Weihong, L.; Hao, L. Biosynthesis of Au nanoparticles using agricultural waste mango peel extract and its in vitro cytotoxic effect on two normal cells. Mater. Lett. 2014, 134, 67-70. [CrossRef]

74. Kumar, S.D.; Singaravelu, G.; Murugan, K.; Ajithkumar, S.; Sivashanmugam, K.; Nicoletti, M.; Benelli, G. Aegiceras corniculatum-Mediated Green Synthesis of Silver Nanoparticles: Biophysical Characterization and Cytotoxicity on Vero Cells. J. Clust. Sci. 2017, 28, 277-285. [CrossRef]

75. Kalpana, D.; Pichiah, P.T.; Sankarganesh, A.; Park, W.S.; Lee, S.M.; Wahab, R.; Cha, Y.S.; Lee, Y.S. Biogenesis of gold nanoparticles using plant powders and assessment of in vitro cytotoxicity in 3T3-L1 cell line. J. Pharm. Innov. 2013, 8, 265-275. [CrossRef]

76. Gogoi, N.; Babu, P.J.; Mahanta, C.; Bora, U. Green synthesis and characterization of silver nanoparticles using alcoholic flower extract of Nyctanthes arbortristis and in vitro investigation of their antibacterial and cytotoxic activities. Mater. Sci. Eng. C 2015, 46, 463-469. [CrossRef] [PubMed]

77. Krishnaraj, C.; Harper, S.L.; Yun, S.-I. In Vivo toxicological assessment of biologically synthesized silver nanoparticles in adult Zebrafish (Danio rerio). J. Hazard. Mater. 2016, 301, 480-491. [CrossRef] [PubMed]

78. Pan, Y.; Neuss, S.; Leifert, A.; Fischler, M.; Wen, F.; Simon, U.; Schmid, G.; Brandau, W.; Jahnen-Dechent, W. Size-dependent cytotoxicity of gold nanoparticles. Small 2007, 3, 1941-1949. [CrossRef] [PubMed]

79. Yu, L.X.; Jiang, W.; Zhang, X.; Lionberger, R.; Makhlouf, F.; Schuirmann, D.J.; Muldowney, L.; Chen, M.L.; Davit, B.; Conner, D.; et al. Novel bioequivalence approach for narrow therapeutic index drugs. Clin. Pharmacol. Ther. 2015, 97, 286-291. [CrossRef] [PubMed]

80. Muller, P.Y.; Milton, M.N. The determination and interpretation of the therapeutic index in drug development. Nat. Rev. Drug Discov. 2012, 11, 751-761. [CrossRef] [PubMed]

81. Huang, X.; Teng, X.; Chen, D.; Tang, F.; He, J. The effect of the shape of mesoporous silica nanoparticles on cellular uptake and cell function. Biomaterials 2010, 31, 438-448. [CrossRef] [PubMed]

82. Nel, A.; Xia, T.; Mädler, L.; Li, N. Toxic potential of materials at the nanolevel. Science 2006, 311, $622-627$. [CrossRef] [PubMed]

83. Yakop, F.; Abd Ghafar, S.A.; Yong, Y.K.; Saiful Yazan, L.; Mohamad Hanafiah, R.; Lim, V.; Eshak, Z. Silver nanoparticles Clinacanthus nutans leaves extract induced apoptosis towards oral squamous cell carcinoma cell lines. Artif. Cells Nanomed. Biotechnol. 2018. [CrossRef] [PubMed]

84. Moher, D.; Shamseer, L.; Clarke, M.; Ghersi, D.; Liberati, A.; Petticrew, M.; Shekelle, P.; Stewart, L.A. Preferred reporting items for systematic review and meta-analysis protocols (PRISMA-P) 2015 statement. Syst. Rev. 2015, 4, 1. [CrossRef] [PubMed] 
85. Kim, S.Y.; Park, J.E.; Lee, Y.J.; Seo, H.-J.; Sheen, S.-S.; Hahn, S.; Jang, B.-H.; Son, H.-J. Testing a tool for assessing the risk of bias for nonrandomized studies showed moderate reliability and promising validity. J. Clin. Epidemiol. 2013, 66, 408-414. [CrossRef] [PubMed]

86. Clark, M.A.; Finkel, R.; Rey, J.A.; Whalen, K. Lippincott's Illustrated Reviews: Pharmacology; Lippincott Williams \& Wilkins: Philadelphia, PA, USA, 2012. 